\title{
Conflicting claims in the eurozone? Austerity's myopia and the need for a European Federal Union in a post-Keynesian eurozone center-periphery model
}

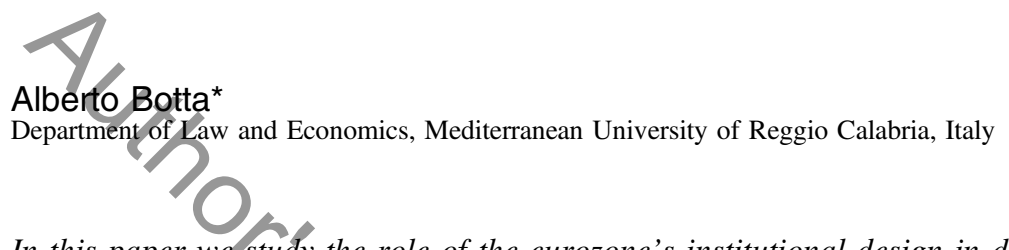

In this paper we study the role of the eurozone's institutional design in determining the sovereign debt crisis of the peripheral euro countries by means of a post-Keynesian eurozone center-periphery model. Within this framework, three points are formally addressed: (1) the incomplete nature of the eurozone with respect to a fully fledged federal union has significantly contributed to generating diverging trends and conflicting claims between central and peripheral eurozone countries in the aftermath of the 2007-2008 financial meltdown; (2) center-periphery diverging trends may disappear and a systemic crisis may occur should financial turbulences deepen in big peripheral economies, possibly spreading to the center; and (3) fiscal austerity does not address the core problems of the eurozone. The creation of a European federal government, capable of implementing anti-cyclical fiscal policies through a federal budget, and of a government banker constitutes the most promising solution to stabilize the macroeconomic picture of peripheral countries and to tackle the crisis. The unlimited bond-buying program recently launched by the ECB is a positive albeit mild step in the right direction away from the extreme monetarism that has shaped eurozone institutions thus far.

Keywords: eurozone debt crisis, post-Keynesian center-peripherymodel

JEL codes: $E 02, H 63$

\section{INTRODUCTION}

Since 2010, economists have devoted increasing efforts to explaining the causes of the eurozone crisis, and to possibly finding a way out. Various opinions have emerged. Among them, some economists indicate the 'original sins in the European Monetary Union (EMU) institutional setup' (Papadimitriou and Wray 2012) as decisive factors which have deepened the current crisis. In 1999, eurozone countries lost monetary

* Email: abotta@eco.unipv.it. I am indebted to Antoine Godin, Clara Capelli, Alberto Russo, Alessia Lo Turco, and two anonymous referees whose comments have significantly improved previous versions of this paper. Of course, I am responsible for any remaining errors. 
sovereignty by adopting the same currency and issuing debt in a currency that they do not control. Furthermore, in the EMU there is no federal institution to support member states in the event of severe economic downturns. Indeed, the EMU works 'much like a US with a FED, but with only individual state treasuries. It would be as if each EMU member country were to attempt to operate fiscal policy in a foreign currency; deficit spending will require borrowing in that foreign currency according to the dictates of private markets' (Wray 1998, pp. 91-92). All these missing elements in the original design of the EMU seriously expose member states to default risk (Papadimitriou and Wray 2012), hence financial turbulences, which would hardly take place in economies that are monetarily sovereign (De Grauwe 2011). The most reasonable way to solve the crisis is the reconciliation of fiscal and monetary policies through a European federal government with monetary sovereignty and a European Central Bank (ECB) acting as a government banker (Palley 2011).

In our view, the above observations cast light on some of the EMU's peculiarities that contribute to making the eurozone vulnerable to financial turmoil. Second, it may explain why a soyereign debt crisis has affected the peripheral eurozone countries even though their performance in terms of macroeconomic fundamentals is often similar or even better than those of other, apparently safer, economies. In this paper, we aim at providing formal support to the aforementioned perspective on the eurozone crisis. We pursue two main goals. First, diverging trends between central and peripheral countries may play a decisive role in defining EMU reforms in the near future. Here, we want to provide a picture of such conflicting claims as emerged in the aftermath of the 20072008 financial crisis; and we want to model the causal relationship connecting them to the aforementioned deficiencies in the EMU original design. Second, we want to show how the creation of a monetarily sovereign European federal union is probably the decisive step ahead in solving the crisis and stabilizing the macroeconomic picture of member states. We will compare such a scenario with the currently prevailing emphasis on fiscal austerity.

We present a post-Keynesian center-periphery eurozone model. The post-Keynesian flavor of our model emerges in several ways and seems tobe justified by two main facts. First, there is some concern among economists as to austerity's contractionary effects on peripheral economies (Krugman 2012). Whilst this point can be hardly grasped by supply-side models, we try to get it by describing economic dynamics as demand-driven. Second, eurozone financial turbulences seem to have all the features of an intertwined sovereign-debt-bank crisis (Stockhammer 2012). Such financial turbulences can have tremendous effects on eurozone economic performances. We provide a formal treatment of this point through a Kaldor-type 'effective credit demand' argument. In our model, we assume that financial distress on sovereign bonds may endanger the solidity of financial institutions' balance sheets. In turn, this may harm economic dynamics via restrictive credit policies by financial institutions.

We adopt a center-periphery framework in light of the recently emerged divergences between central and peripheral euro countries. We distinguish between a center-small periphery scenario and a center-big periphery scenario. Our purpose is to assess whether the crisis in the periphery could propagate to the center depending on the intensity of center-periphery linkages. Center-periphery models are not new in the post-Keynesian tradition. Hein et al. (2011) already presented a Thirlwall-type model that aimed to address balance-of-payments disequilibria inside the eurozone. Considering the previous works in this tradition, our model focuses on the financial side of the story. It focuses on macroeconomic variables such as debt-to-GDP ratios, country-risk premia and interestrate spreads. Since 2010, these terms have entered everyday debates among citizens, 
economists and policymakers. Here we try to account for the importance these variables seem to have recently acquired in determining economic dynamics and in defining economic policies in eurozone countries.

\section{DIVERGING TRENDS IN THE EUROZONE}

Until 2007, signs of convergence between central and peripheral economies had emerged in the eurozone. Relevant capital inflows to peripheral countries boosted growth and allowed them to catch up with central economies. Zero-approaching interest-rate spreads mirrored the confidence of financial markets in the solidity of peripheral countries' development. However, remarkable structural asymmetries with respect to the center were still present. Tables A1-A2 and Figures A1-A4 in Appendix A1 provide some evidence on this point.

First, economic growth in peripheral economies was largely based on mounting, likely unsustainable, housing booms. This was clear in Spain and Ireland. In 2006, the share of the construction sector in Spanish GDP was three times higher than that recorded in Germany (see Table A1). Center-periphery asymmetries were even wider in the case of Greece and Portugal. Both economies are poorly integrated on international goods markets and show a low propensity to export. Manufacturing is considerably limited given their degree of development. By contrast, Table A1 confirms the strength of manufacturing in Germany and the much higher capability to export which is characteristic of both large and small central economies.

Second, huge current account deficits emerged as a side-product of economic booms in the periphery (see Figure A1). While peripheral economies were accumulating increasing external debt stocks, centraleconomies' foreign assets were rising much faster than their liabilities. According to the IMF (2012), at the end of 2011, German positive net investment foreign position (NIEP) amounted to 36 percent of GDP. With the exception of Italy, in the same period all peripheral economies were registering negative NIFPs far higher than 50 percent of GDP.

The 2007-2008 financial meltdown has clearl revealed the fragilities of the peripheral euro economies. Although recession affected the entire EMU, downturns were particularly severe in the peripheral countries that had previously experienced housing booms. In the case of Greece and Portugal, a low propensity to export further deepened the recession by impeding a quick export-led recovery. Furthermore, peripheral governments have had to massively intervene to prevent the collapse of the financial system and provide a safety net against widespread unemployment. As a result, as seen in Figures A2 and A3, public deficits and debt stocks soared sharply, móre intensively in the periphery than in the center. Within such a gloomy scenario, financial markets suddenly changed their minds. While peripheral euro countries have emerged as the epicenter of worldwide financial instability, central economies have turned out to be safe havens in the eyes of financial investors. Accordingly, liquidity has rapidly dried up in the periphery and moved to the center. The previous convergence set the stage for widening diversities. Interest rates in the periphery and center-periphery spreads have increased astonishingly. Figure A4 shows the asymmetric reaction of financial markets in the peripheral eurozone countries with respect to central economies, and other advanced countries in the aftermath of the 2007-2008 financial shock.

All these events seem to describe a standard center-periphery balance-of-payments crisis taking place inside the eurozone (Hein et al. 2011; Perez-Caldentey and Vernengo 2012; Bibow 2012). While such a perspective gets some relevant aspects of the current 
difficulties in peripheral countries, there is something missing. Following De Grauwe (2011), a look at macroeconomic data does not explain why financial turbulence is afflicting a peripheral euro country like Spain and not the UK. Since 2007, economic growth in the UK has been disappointing; public balance deficits have been generally higher than those observed in Spain; the UK current account has persistently recorded deficits; and the UK debt-to-GDP ratio is closely similar to the Spanish one. The same doubts emerge if we compare the eurozone as a whole to the US. The crucial point that can explain such a paradox may lie in the differences between the EMU and monetarily sovereign countries in terms of the institutions designed to implement economic policies. In particular, we refer to the absence of a eurozone federal government implementing anti-cyclical fiscal policies, and of a fully fledged eurozone central bank acting as a government banker (Palley 2011). Let's try to discuss this point more formally.

\subsection{A center periphery eurozone model}

Consider a well-developed center country and a relatively less-developed periphery country. They share the same currency and have delegated monetary policy to a common central bank. The two countries maintain complete fiscal independence concerning anti-cyclical measures. Fiscal deficits are financed by issuing national treasury bonds denominated in the same euro currency. There is no European federal fiscal authority that imposes taxes, makes expenditures, or collects resources by issuing federal bonds.

Some recent empirical analyses attribute emphasis to the Keynesian multiplier and effective demand as relevant factors to explain the current crisis in several developed countries (Corsetti et al. 2012). This approach goes hand-in-hand with the concern about the contractionary effects of austerity in the eurozone (Krugman 2012). Accordingly, in this paper I model economic activity in the center and in the periphery as demand-driven. For the sake of simplicity, I follow Layoie (2006) and assume an IS-growth curve in which the growth rates of the center and the periphery are functions of demand injections and leakages:

$$
\begin{aligned}
& g_{C}=f_{C}\left(G_{C}\left(d_{C}\right), E X_{C}, I_{C}\left(P_{C}^{T}\left(i_{C}\left(\sigma_{C}\right)\right), P_{P}^{T}\left(i_{P}\left(\sigma_{P}\right)\right)\right), \theta_{C}\left(d_{C}\right)\right)^{1} \\
& g_{P}=f_{P}\left(G_{P}\left(d_{P}\right), E X_{P}, I_{P}\left(P_{P}^{T}\left(i_{P}\left(\sigma_{P}\right)\right), P_{C}^{T}\left(i_{C}\left(\sigma_{C}\right)\right)\right), \theta_{P}\left(d_{P}\right)\right) .
\end{aligned}
$$

Equations (1) and (2) show that the current growth rate of the center $g_{C}$ and of the periphery $g_{P}$ positively depend on domestic public expenditures $G_{C}\left(G_{P}\right)$, current net exports $E X_{C}\left(E X_{P}\right)$, and total investment $I_{C}\left(I_{P}\right) . \theta_{C}$ and $\theta_{P}$ stand for fiscal policy parameters linked to taxation. The link between $g_{C}\left(g_{P}\right)$ and $\theta_{C}\left(\theta_{P}\right)$ is negative. An increase in taxation in the center (periphery) - that is, a higher value of $\theta_{C}\left(\theta_{P}\right)$ - reduces the Keynesian multiplier and, ceteris paribus, the growth rate $g_{C}\left(g_{P}\right)$.

1. In a more realistic discrete time model, we define current output $\left(Y_{t}\right)$ as: $Y_{t}=m\left(I_{t}+G_{t}+E X_{t}\right)$, where $m$ stands for the Keynesian multiplier. Noting that $Y_{t}=Y_{t-1}\left(1+g_{t}\right)$, we can write the growth rate of real GDP at time $t$ as: $g_{t}=m\left(\eta_{I} g_{t}^{I}+\eta_{G} g_{t}^{G}+\eta_{E X} g_{t}^{E X}\right)$. In our formulation, $g_{t}^{I}, g_{t}^{G}$ and $g_{t}^{E X}$ are the growth rates of total investment $(I)$, public expenditures $(G)$ and economy's exports $(E X) ; \eta_{I}, \eta_{G}$ and $\eta_{E X}$ are the corresponding shares of GDP. Ceteris paribus, the higher $I_{t}, G_{t}$ and/or $E X_{t}$, the better the growth performance of the economy as a whole. 
Equations (1) and (2) also read that a negative relationship might exist between the growth rates $g_{C}$ and $g_{P}$, and the debt-to-GDP ratios $d_{C}$ and $d_{P}$, respectively. In this paper, however, such a relationship does not represent any alleged 'natural' negative effect of (high) debt-to-GDP ratios on economic growth, as was purported by Reinhart and Rogoff (2010) in their largely criticized empirical analysis. ${ }^{2}$ Rather, it ought to be conceived as a policy-induced relationship that emerges from the eurozone institutional rules regulating euro countries' fiscal policies. Following Taylor et al. (2012), the EMU seems to be currently engulfed by a sort of hysteria to reduce public debts. These feelings emerge clearly from the Maastricht Treaty and the 1997 Stability and Growth Pact, and are even strengthened by the fiscal compact. The fiscal compact imposes tough fiscal corrections and huge public debt cuts in countries with high debt-to-GDP ratios. It also gives slightly more space for implementing expansionary policies to minimally indebted economies. According to Keynesian lines, these prescriptions can have a strong impact on the economic activity of the eurozone via public expenditure cuts and/or increasing taxation. The formulation of Equations (1) and (2) aims at modeling these feelings, and their possible implications on economic growth in the EMU.

According to the endogenous monetary theory, investment does not come from savings. On the one hand, investment depends on entrepreneurs' animal spirits. On the other hand, investment is affected by banks' credit policies, which define the effective demand for credit on the soundness of banks' assets. With this in mind, Equation (1) assumes that economic growth in the center is indirectly affected by the prices of both center and periphery governments' bonds, $\left(P_{C}^{T}\right)$ and $\left(P_{P}^{T}\right)$ respectively, which in turn depend negatively on the interest rates $i_{C}$ and $i_{P}$. Changing the prices of governments' bonds will alter the solidity of banks' balance sheets and therefore their credit policy. Investment demand will inevitably be affected by easing or tightening conditions on the credit market.

Peripheral euro countries are net receivers of foreign capital. Yet, big peripheral economies such as Spain and Italy have aceumulated significant asset positions in the center (Waysand et al. 2010). Accordingly, Equation (2) assumes both peripheral and central bonds to be in the balance sheets of peripheral banks and therefore to influence, via banks' credit policy, domestic investment $I_{P}$.

In Equations (1) and (2), interest rates $i_{C}$ and $i_{P}$ are influenced by $\sigma_{C}$ and $\sigma_{P}$, respectively. In our model, they represent country-specific risk indicators that financial operators assign to assets issued by eurozone countries. Parameter $\sigma_{C}$ represents the risk perceived by financial markets in acquiring a central economy government's bond. Parameter $\sigma_{P}$ encompasses all the country-specific factors taken into account by financial investors when buying a peripheral government's bond. Such countryspecific factors influence the remuneration gained on bonds' holdings. In particular, they determine the spread between the interest rate $i_{C}\left(i_{P}\right)$ and the interest rate $i$ "associated with a third-country riskless financial asset, say US government Treasury Bills. This point is modeled in Equations (3) and (4): ${ }^{3}$

$$
i_{C}=i^{*}+\sigma_{C}
$$

2. See Herndon et al. (2013) for a detailed critique of the empirical analysis carried out in Reinhart and Rogoff (2010).

3. For the sake of simplicity, we neglect the euro-dollar exchange rate risk in Equations (3) and (4). We do this in order to stress the relevance of financial transactions among different euro countries' bonds instead of capital flights from eurozone assets towards third-countries' financial activities. In this sense, it is worth noting the fairly small devaluation of the euro with respect to the dollar, in spite of the considerable distress afflicting European financial markets since 2010. 


$$
i_{P}=i^{*}+\sigma_{P}
$$

In this paper, we model inflation at country level in a standard accelerationist fashion:

$$
\begin{aligned}
& \pi_{C}=\pi^{T}+\psi\left(g_{C}-g_{C}^{n}\right) \\
& \pi_{P}=\pi^{T}+\chi\left(g_{P}-g_{P}^{n}\right) .
\end{aligned}
$$

Equation (5) reads that the current inflation in the center $\pi_{C}$ is equal to the inflation target $\pi^{T}$ established by the ECB in the event that current growth $g_{C}$ is equal to the central economy potential growth rate $g_{C}^{n}{ }^{4}$ Should $g_{C}$ be higher (lower) than $g_{C}^{n}$, inflation in the center will be higher (lower) than the long-run inflation rate pursued by European monetary authorities. The same line of reasoning applies to Equation (6), which defines current inflation in the periphery $\pi_{P}$. In Equation (6), $g_{P}^{n}$ stands for potential growth in the periphery. Parameters $\psi$ and $\chi$ represent the sensitivity of inflation dynamics to the output gap in the center and the periphery.

Once $g_{C}, g_{P}, i_{C}, i_{P}, \pi_{C}$ and $\pi_{P}$ are defined in Equations (1)-(6), the medium-to-long run dynamics of the model comes from Equations (7)-(10). Equations (7) and (8) describe the dynamics of the debt-to-GDP ratio $d_{C}{ }^{5}$ and of the country-risk factor $\sigma_{C}$ in the center:

$$
\begin{aligned}
& \dot{d_{C}}=d_{C}\left(\widehat{D_{C}}-\pi_{C}-g_{C}\right) \\
& =d_{C}\left[\frac{\Omega_{C}\left(G_{C}\left(d_{C}\right), \theta_{C}\left(d_{C}\right), g_{C}\left(G_{C}, \theta_{C}\right)\right.}{d_{C}}\right] \\
& \dot{\sigma_{C}}=\beta\left(d_{C}-\overline{d_{C}}\left(d_{C}^{*}\left(\sigma_{C}\right), \varepsilon_{P}\right)\right) \\
& \text { with } \overline{d_{C}}=d_{C}^{*} \text { if } \varepsilon_{P}=0 ; \overline{d_{C}}>d_{C}^{*} \text { if } \varepsilon_{P}>0 .
\end{aligned}
$$

Equation (7) defines the time derivative of the central economys debt-to-GDP ratio $\dot{d}_{C}$. According to the term in square parentheses, $\dot{d}_{C}$ is a positive function of $\frac{\Omega_{C}}{d_{C}}$, with $\Omega_{C}$ as the primary deficit-to-GDP ratio. The primary deficit $\Omega_{C}$ depends on public expenditures $G_{C}$, the tax parameter $\theta_{C}$, and the current growth rate $g_{C}$. Higher public expenditures can stimulate economic growth, thus inducing higher tax revenues and lower deficits. Nevertheless, such an indirect negative effect of $G_{C}$ on $\Omega_{C}$ is likely to be smaller than its direct positive impact via government outlays. Here we assume an overall positive link between $\Omega_{C}$ and $G_{C}$ to exist. By contrast, the primary deficit $\Omega_{C}$ is a negative function of the tax parameter $\theta_{C}$, and of the current growth rate $g_{C}$.

4. In this paper, we assume $g^{n}$ to be exogenous in order to allow the model to remain mathematically tractable. Yet it could be endogenized, so that $g_{C}^{n}=g_{C}, g_{P}^{n}=g_{P}$, and $\pi^{T}=\pi_{C}=\pi_{P}$ in the long run. See León-Ledesma and Thirlwall (2002), Lavoie (2006), and Botta (2013) on this point.

5. In Equation (7), $\widehat{D_{C}}$ is the percentage variation in the central economy's debt stock. 
In Equation (7), $\dot{d}_{C}$ is positively affected by the interest rate $i_{C}$. Ceteris paribus, the higher $i_{C}$ is, the higher the service cost of outstanding debt and the need for new bond issuances will be, hence $\dot{d}_{C}$. On the contrary, a higher inflation target $\pi^{T}$ and a faster economic growth $g_{C}$ will reduce $d_{C}$ by raising the nominal GDP via real and nominal channels. Finally, a negative link exists between $\dot{d}_{C}$ and the potential growth rate $g_{C}^{n}$. Ceteris paribus, the higher $g_{C}^{n}$ and the connected output gap are, the lower domestic inflation or the higher the risk of deflation will be. A Fisher-type debt-deflation process could take place, destabilizing the debt-to-GDP ratio.

Equation (8) describes how financial operators may periodically update the financial risk indicator attached to the center. We assume the central economy's risk indicator to be revised by confronting the outstanding debt-to-GDP ratio $d_{C}$ with some benchmark level $\overline{d_{C}}$. According to Equation (8), if $d_{C}$ is higher (lower) than the benchmark level $\overline{d_{C}}$, financial operators will increase (reduce) the financial risk indicator $\sigma_{C}$, so that ${\dot{\sigma_{C}}}_{C}>0$ $\left(\dot{\sigma}_{C}<0\right)$. Parameter $\beta$ stands for the sensitivity of financial operators' feelings to any gap between the current debt-to-GDP ratio and the benchmark level $\overline{d_{C}}$.

In this model we assume that the debt-to-GDP target $\overline{d_{C}}$ positively depends on two factors: $d_{C}^{*}$ and $\varepsilon_{\hat{p}}$. First, $d_{C}^{*}$ is the debt-to-GDP ratio consistent with the economy growing at full potential. It represents the sort of long-run equilibrium level of the debt-to-GDP ratio the economy will tend to reach once growth is at the potential rate $g_{C}^{n}$ and, consequently, primary deficit is at its structural level. The full potential debt-to-GDP ratio is defined as $d_{C}^{*}=\frac{\Omega_{C}^{*}}{\left(g_{C}^{n}+\pi^{T}-i^{*}-\sigma_{C}\right)}$, where $\Omega_{C}^{*}$ is the primary deficitto-GDP ratio at its structural level.

In times of financial stability, we assume financial operators will set the benchmark level $\overline{d_{C}}$ equal to the full potential debt-to-GDP ratio $d_{C}^{*}$ (that is, $\varepsilon_{P}=0$ ). However, in times of financial distress, financial operators may also consider 'exogenous' factors to evaluate financial risks in the center. Assume, for instance, that some bad news were to come from the periphery: as a consequence of the 2007-2008 financial shock, the periphery is experiencing a deep recession and large public balance deficits. Financial operators may start to worry about the structural weaknesses of the periphery, even though they had been mostly neglected in times of bonanza. Capital may rapidly leave the periphery in search of a safe haven in the center. In Equation (8), the term $\varepsilon_{P}$ aims to get this point. In times of financial distress, we assume $\varepsilon_{P}$ to become positive. Financial operators increase the benchmark level $\overline{d_{c}}$. Regardless of the gap between $d_{C}$ and $d_{C}^{*}$, and of the effective financial solidity of the center, financial markets will move capital away from the periphery and towards the center and reduce the center's risk factor $\sigma_{C}$.

Equations (9) and (10) correspond to Equations (7) and (8), and now refer to the periphery:

$$
\begin{gathered}
\dot{d}_{P}=d_{P}\left(\widehat{D_{P}}-\pi_{P}-g_{P}\right) \\
=d_{P}\left[\frac{\Omega_{P}\left(G_{P}\left(d_{P}\right), \theta_{P}\left(d_{P}\right), g_{P}\left(G_{P}, \theta_{P}\right)\right)}{d_{P}}+i_{P}-\pi^{T}-(1+\chi) g_{P}+\psi g_{P}^{n}\right] \\
\dot{\sigma_{P}}=\delta\left(d_{P}-\overline{d_{P}}\left(d_{P}^{*}\left(\sigma_{P}\right), \varepsilon_{P}\right)\right)
\end{gathered}
$$

with $\overline{d_{P}}=d_{P}^{*}$ if $\varepsilon_{P}=0 ; \overline{d_{P}}<d_{P}^{*}$ if $\varepsilon_{P}>0$. 
Equations (9) and (10) describe the dynamics of the debt-to-GDP ratio $d_{P}$ and of the country-risk factor $\sigma_{P}$ in the periphery along similar lines as those assumed in the center. Note, however, that there is a fundamental asymmetry. Actually, adverse shocks hitting the periphery (that is, $\varepsilon_{P}>0$ ) will be immediately passed through a value of $\overline{d_{P}}$ lower than $d_{P}^{*}$. Accordingly, huge capital outflows will take place and the periphery's financial risk indicator $\sigma_{P}$ will be revised upward.

Equations (7)-(10) give rise to a complex four-equation dynamic system. In order to keep our analysis as simple as possible, for the time being let's consider the sets of equations (7)-(8) and (9)-(10) as independent, except for the 'shock' term $\varepsilon_{P}$. Further, let us focus on the stability analysis on the center only, and analyse the Jacobian matrix $J_{C}$ (evaluated at the steady state). We report a detailed mathematical analysis of dynamic stability in the center in Appendix A2. Figure 1 below describes the economic dynamics in the center graphically.

The top-right panel in Figure 1 portrays the two loci for constant values of the debtto-GDP ratio $d_{C}$ and country risk factor $\sigma_{C}$. The $\left(\dot{d}_{C}=0\right)$ locus is an inverted U-shaped curve. The $\left(\dot{\sigma}_{C}=0\right)$ locus is an upward sloping curve with a horizontal asymptote when $\sigma_{C}=\left(g_{C}^{n}+\pi^{T}-i^{*}\right)$ and $\overline{d_{C}}=d_{C}^{*}=\frac{\Omega_{C}^{*}}{\left(g_{C}^{n}+\pi^{T}-i^{*}-\sigma_{C}\right)}=\infty$. Further, we assume it to have a horizontal segment, with $\sigma_{C}=0$, when $d_{C}$ is lower than $d_{C\left(\sigma_{C}=0\right)}^{*}=\frac{\Omega_{C}^{*}}{\left(g_{C}^{n}+\pi^{T}-i^{*}\right)}$.

Note two intersection points, hence the possibility for multiple equilibria to exist. Equilibrium $A$ features a lower debt-to-GDP ratio $d_{C}^{1}$, a lower country-specific risk indicator $\sigma_{C}{ }^{1}$ and a higher growth rate $g_{C}{ }^{1}$ than the records associated with equilibrium $B$. Furthermore, while point $A$ shows stable dynamics in its neighborhoods, equilibrium $B$ is unstable. Equilibrium $B$ may represent a sort of risky economic environment, the

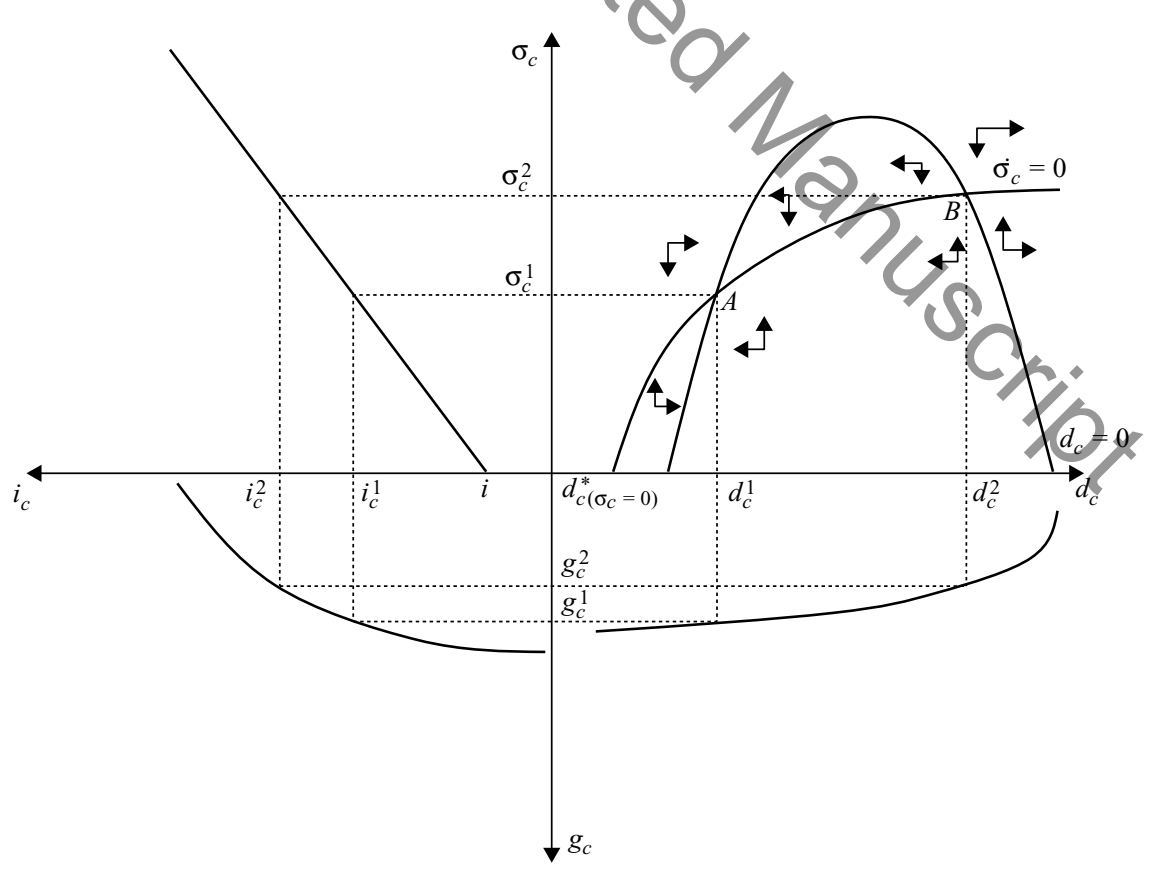

Figure 1 The case for multiple long-run equilibria 
pre-crisis Greek context for instance, in which a temporary economic shock may well be enough to generate explosive dynamics in the debt-to-GDP ratio.

Moving counter-clockwise in Figure 1, the remaining panels describe the economic mechanisms connecting $d_{C}$ to $g_{C}$. In the top-left panel, we portray Equation (3). In the bottom-left panel, we depict the IS-growth curve, shown as a concave curve. This representation may be consistent with some recent empirical evidence on a variable Keynesian multiplier featuring higher values during financial crises and economic recessions (Corsetti et al. 2012). Accordingly, the higher $i_{C}$ due to financial turbulences on the market for bonds, the deeper the economic recession will be due to a reduction in investment $I_{C}$ and a sharp (negative) multiplicative effect on the overall effective demand.

In the bottom-right panel we match debt-to-GDP ratios and GDP growth rates associated withlong-run equilibria. Once again, note that the negative relationship between $g_{C}$ and $d_{C}$, the number of the equilibria, and their stability properties mostly depend on the current eurozone political-institutional 'paranoia' about public debt reduction, and on the incomplete eurozone's institutional design with respect to a monetarily sovereign political entity. First, tough austerity packages (that is, lower values of $G_{C}\left(G_{P}\right)$ and/or higher values of $\left.\theta_{C}\left(\theta_{p}\right)\right)$, as imposed by European rules on fiscal discipline in the presence of high debt-to-GDP ratios, can produce a huge drop in the growth rate $g_{C}$, in particular when fiscal retrenchment is implemented during recessions. The ensuing reduction in the primary deficit $\Omega_{C}$ may not be enough to significantly cut $\left(\Omega_{C} / d_{C}\right)$ if the debtto-GDP ratio is too high. Eventually, too much emphasis on debt cuts generates the downward-sloping arm in the locus for $\left(\dot{d}_{C}=0\right)$, hence the unstable dynamics portrayed in Figure 1. Second, financial markets would not react nervously to increasing debt-toGDP ratios should public debt issuances be largely centralized at a federal European level, and be possibly supported by the action of a government central banker.

It is easy to see that the policy implications of our framework are opposite with respect to those put forward by Reinhart and Rogoff (2010). First, public debt management may not be a priority in peripheral eurozone countries, and austerity is likely to turn out to be a self-defeating measure to ensure fiscal solidity. By contrast, a more gradual approach to fiscal imbalance and higher attention in sustaining growth could avoid the negative link between $g_{C}$ and $d_{C}$, and strengthen macroeconomic stability. Second, the current sovereign debt crisis can successfully be tackled if the eurozone undertakes all the steps needed to become a monetarily sovereign political entity. In this case, an upward-sloping locus for $\left(\dot{d}_{C}=0\right)$ could emerge in Figure 1. It might cross a much flatter locus for $\left(\dot{\sigma}_{C}=0\right)$ once or three times, giving rise to one or more stable equilibria. In both cases, faster economic growth would be more likely achieved, and explosive dynamics in the debt-to-GDP ratio avoided.

\section{CENTER-PERIPHERY DYNAMICS AFTER THE 2007-2008 FINANCIAL MELTDOWN}

\subsection{The center-small periphery case}

Let's now consider the implications of our model in terms of center-periphery dynamics. Let's consider a center-small periphery scenario first.

Imagine a large central economy - Germany - and a small periphery - Greece. According to the empirical evidence on the eurozone, imagine that economic links between the two countries are weak. First, reciprocal export flows amount to a negligible proportion of their own total exports, so that $\left(\frac{\partial g_{C}}{\partial E X_{C}} \frac{\partial E X_{C}}{\partial E X_{C} \rightarrow S P}=0\right)$ and 


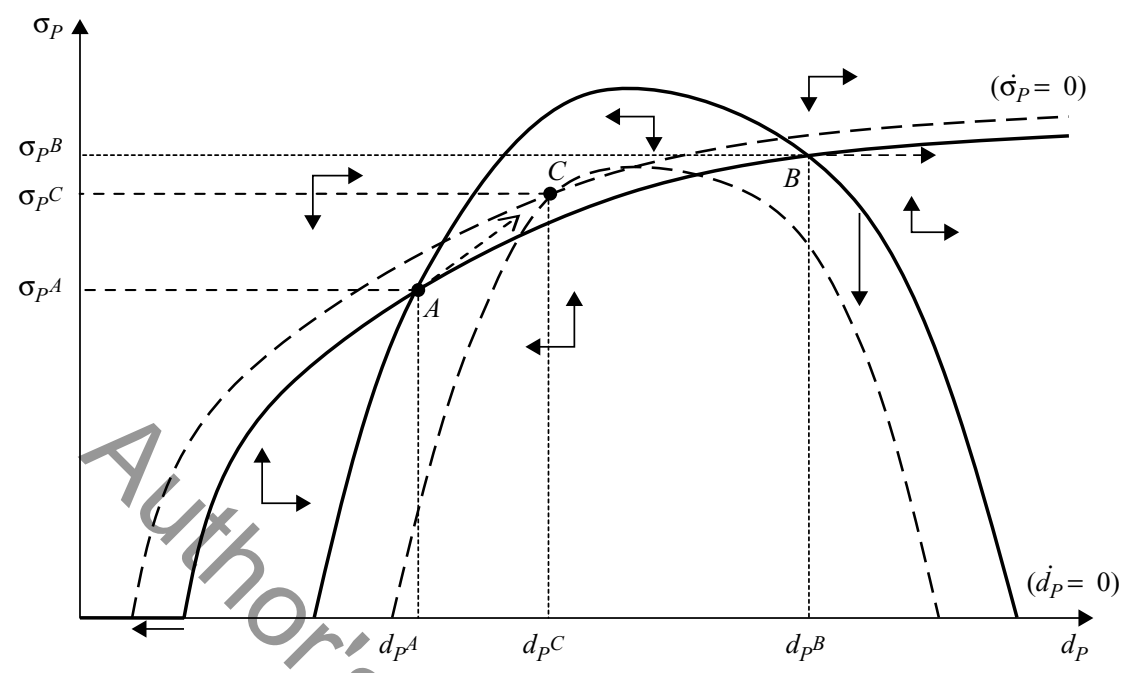

Figure $2 a$ A center-small periphery scenario: long-run dynamics in the small periphery

$\left(\frac{\partial g_{P}}{\partial E X_{S P}} \frac{\partial E X_{S P}}{\partial E X_{S P} \rightarrow C}=0\right) \cdot{ }^{6}$ Second, even though overall financial markets' response to bad news in the periphery can have significant economic consequences, direct centerperiphery financial links are negligible. Assume the center economy's foreign assets in the small periphery do not have much weight in center financial institutions' balance sheets, so that $\left(\frac{\partial g_{C}}{\partial I_{C}}\right)\left(\frac{\partial I_{C}}{\partial P_{P}^{T}}\right)=0 .^{7}$ Apply this line of reasoning also to the small periphery's asset holdings in the center, so that $\left(\frac{\partial_{P} P}{\partial I_{P}}\right)\left(\frac{\partial I_{P}}{\partial P_{C}^{T}}\right)=0$.

Now assume that the 2007-2008 financial shock occurs, curtailing growth and increasing public deficits in both economies. In a two-country version of Figure 1, such events induce both loci for $\left(\dot{d}_{C}=0\right)$ and $\left(\dot{d}_{P}=0\right)$ to move downward due to reductions in $g_{C}$ and $g_{P}$, and increases in $\Omega_{C}$ and $\Omega_{P}$. However, due to center-periphery asymmetries, the economic downturn in the periphery is deeper and lasts longer compared to recession in the center. The periphery's public finances register deeper imbalances than abroad. Accordingly, the locus for $\left(\dot{d}_{P}=0\right)$ will move far further down than the locus for $\left(\dot{d}_{C}=0\right)$ will do. We depict these facts in Figures $2 \mathrm{a}$ and $2 \mathrm{~b}$.

Furthermore, capital markets do not react neutrally to the common center-periphery shock. In Equations (8) and (9), factor $\varepsilon_{P}$ assumes a positive value. In the periphery, an upward revision of factor $\sigma_{P}$ will take place. Central economy bonds, by contrast, will

6. $E X_{C \rightarrow S P}\left(E X_{S P \rightarrow C}\right)$ stands for the center's (small periphery's) exports towards the small periphery (center).

7. By September 2011, according to the Joint External Debt Hub (JEDH), German banks' exposure in Italy and Spain amounted to 67 percent of overall German security holdings in peripheral countries. In light of this evidence, the above assumptions must be seen in a comparative perspective as a way to remark differences between a soft crisis scenario, in which small peripheral countries only risk default, and a much more worrisome crisis in which financial turbulences dramatically increase in big peripheral economies as well. 


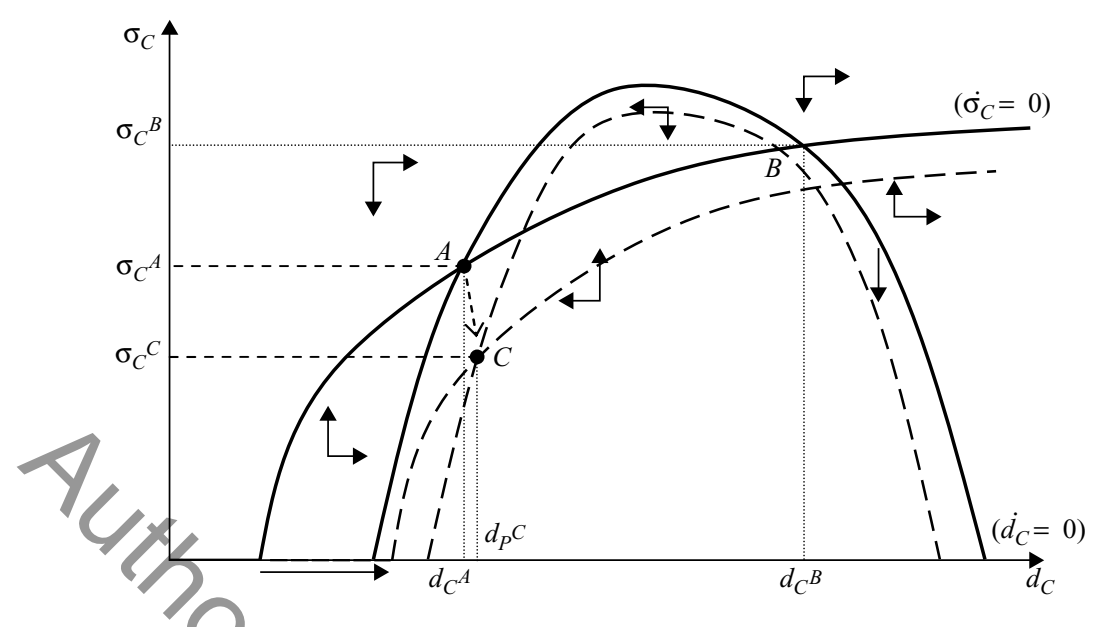

Figure $2 b$ A center-small periphery scenario: long-run dynamics in the center

get higher ratings and the country-risk factor $\sigma_{C}$ will decrease. Graphically, such asymmetric behaviors of financialmarkets are depicted through opposite movements in the loci for $\left(\dot{\sigma}_{P}=0\right)$ and $\left(\dot{\sigma}_{C}=0\right)$. In Figure $2 \mathrm{a}$, the locus for $\left(\dot{\sigma}_{P}=0\right)$ will move to the left. In Figure $2 b$, the locus for $\left(\dot{\sigma}_{c}=0\right)$ will shift to the right.

At the end of the day, a higher public deficit (higher values of $\Omega_{P}$ ), economic recession (a lower $\left.g_{P}\right)$, and financial turbulences $\left(\varepsilon_{P}>0\right)$ all induce substantial increases in the debt-to-GDP ratio $d_{P}$, and in the risk factor $\sigma_{P}$ in the periphery. As a consequence of the initial shock, the periphery seriously-risks a permanent move from equilibrium $A$ to the new equilibrium $C$, in which much higher interest rates will go hand-in-hand with far lower growth rates compared to the pre-crisis period.

Even worse, should the periphery be initially located in the unstable equilibrium $B$, as perhaps is the case with Greece, the above events could generate destabilizing dynamics and eventually lead the country to bankruptcy Note that this could also happen in seemingly safer countries, such as Spain and Ireland, in the event that financial markets' reactions to the crisis were so strong as to lead the twoloci for $\left(\dot{\sigma}_{P}=0\right)$ and $\left(\dot{d}_{P}=0\right)$ to no longer intersect. A set of conditions leading to such an event reads:

$$
\begin{aligned}
& \frac{\Omega_{P}^{*}}{\left(g_{P}^{n}+\pi^{T}-i^{*}\right)}<\frac{\Omega_{P}}{\left[(1+\psi) g_{P}+\pi^{T}-i^{*}-\psi g_{P}^{n}\right]} \text { and } \\
& -\frac{\left[\frac{\left(\frac{\partial \Omega_{P}}{\partial d_{P}}\right) d_{P}-\Omega_{P}}{d_{P}^{2}}-(1+\psi) \frac{\partial g_{P}}{\partial d_{P}}\right]}{\left[1+\frac{\left(\frac{\partial \Omega_{P}}{\partial g_{P}}\right)\left(\frac{\partial g_{P}}{\partial \sigma_{P}}\right)}{d_{P}}-(1+\psi) \frac{\partial g_{P}}{\partial \sigma_{P}}\right]}<\frac{1}{\left[\frac{\Omega_{P}^{*}}{\left(g_{P}^{n}+\pi^{T}-i^{*}-\sigma_{P}\right)^{2}}\right]}
\end{aligned}
$$


The above two conditions tell us that the lower the structural primary deficit $\Omega_{P}{ }^{*}$, perhaps as established by the European authorities into the fiscal compact, the more likely is overall instability to occur. Further, tough austerity packages that sharply hamper growth (that is, high values of $\left.\left(\partial g_{P} / \partial d_{P}\right)\right)$, and severe effects of financial turmoil on the real side of the economy (that is, high values of $\left.\left(\partial g_{P} / \partial \sigma_{P}\right)\right)$ are all conducive to a highly unstable economic environment. Austerity may turn out to be a source of instability, rather than its remedy.

In the center, a radically different picture emerges. The crisis-driven downward movement in the locus for $\left(\dot{d}_{C}=0\right)$ can induce the debt-to-GDP ratio to increase. However, capital flights towards the center may tame such a trend. A slightly increasing debt-to-GDP ratio may paradoxically combine with a lower country risk factor, easing conditions on credit markets and causing growth to rebound. This is depicted in Figure $2 b$. It resembles well what is going on in a large central economy such as Germany. Thanks to the abundance of liquidity on domestic financial markets, German Bunds' interest rates are at never-seen-before low values, and a considerable economic recovery has occurred in 2010 and 2011. The German debt-to-GDP ratio seems to have stabilized at around 83 percent since 2010. The center's (positive) economic performance with respect to the small periphery appears clearly.

\subsection{The center-big periphery case}

Now consider a much more complex center-big periphery scenario. First, trade relationships between the two countries are likely stronger than in the case of the small periphery. Indeed, economic recession in Italy will likely have significant negative effects on economic dynamics in Germany. In our model, this implies that $\left(\frac{\partial g_{C}}{\partial E X_{C}} \frac{\partial E X_{C}}{\partial E X_{C} \rightarrow B P}>0\right)^{8}$ and vice versa. Second, the central economy's asset holdings in the big periphery are much more substantial than those in the small economies. Therefore, the financial system of the center will be hardly immune to a mounting crisis in the periphery. A perverse cycle between bankruptcies in the periphery and financial dislocation in the center will probably take place, with obvious negative consequences on investment in both economies. Accordingly, we assume $\left(\frac{\partial g_{C}}{\partial I_{C}}\right)\left(\frac{\partial I_{C}}{\partial P_{P}^{T}}\right)>0$ and $\left(\frac{\partial g_{P}}{\partial I_{P}}\right)\left(\frac{\partial I_{P}}{\partial P_{C}^{T}}\right)>0$.

We formally analyse the center-big periphery dynamics in Appendix A3. What emerges from our analysis is that overall stability cannot be assured in a center-big periphery context. Both systems could be stable if considered individually. Instability, however, is likely to emerge due to the financial links connecting the two countries The more financially integrated countries are and the more exposed single-country credit institutions are to financial turbulences in the partner country, the higher the likelihood that financial instability in the big periphery will extend to the center. We depict such an event in Figures $3 a$ and $3 b$, where the onset of the crisis follows the same lines seen in the case of a small periphery. However, initial center-periphery divergences may be rapidly replaced by similar dynamics. This happens when degrading financial conditions in the periphery start to impinge upon financial institutions' solidity in the center, hence curtailing economic growth $g_{C}$, and raising public balance disequilibria $\Omega_{C}$. In Figures $3 \mathrm{a}$ and $3 \mathrm{~b}$, such perverse mechanisms are represented by a sequence of downward movements in the two loci for $\left(\dot{d}_{C}=0\right)$ and $\left(d_{P}=0\right)$, which will now feed back into each other and spread financial and economic crisis in the overall eurozone. If such

8. $E_{C \rightarrow B P}\left(E_{B P \rightarrow C}\right)$ stands for center (peripheral) exports towards the big periphery (center). 


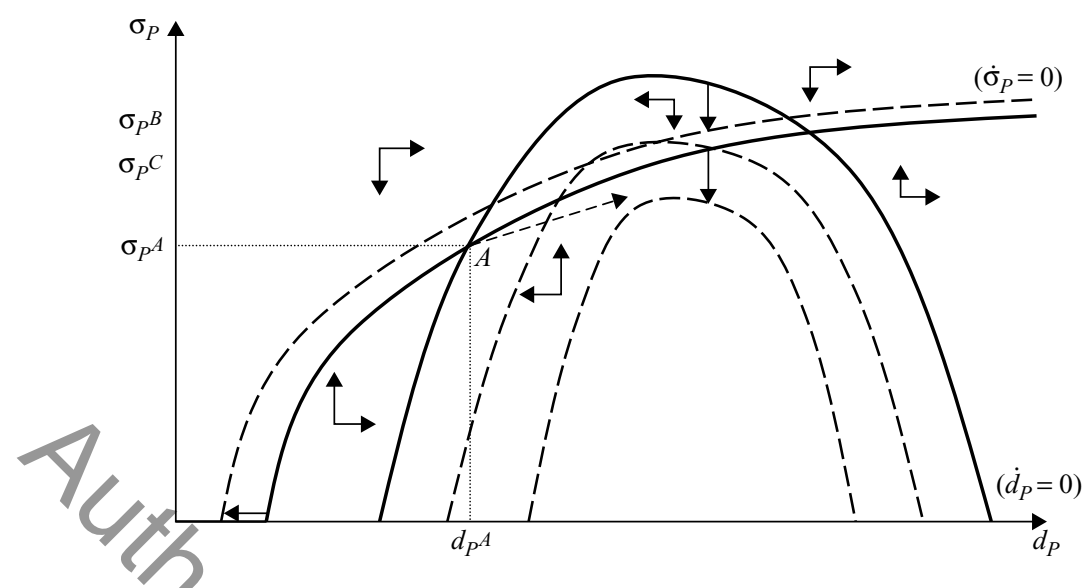

Figure $3 a$ The periphery's financial instability in the center-big periphery case

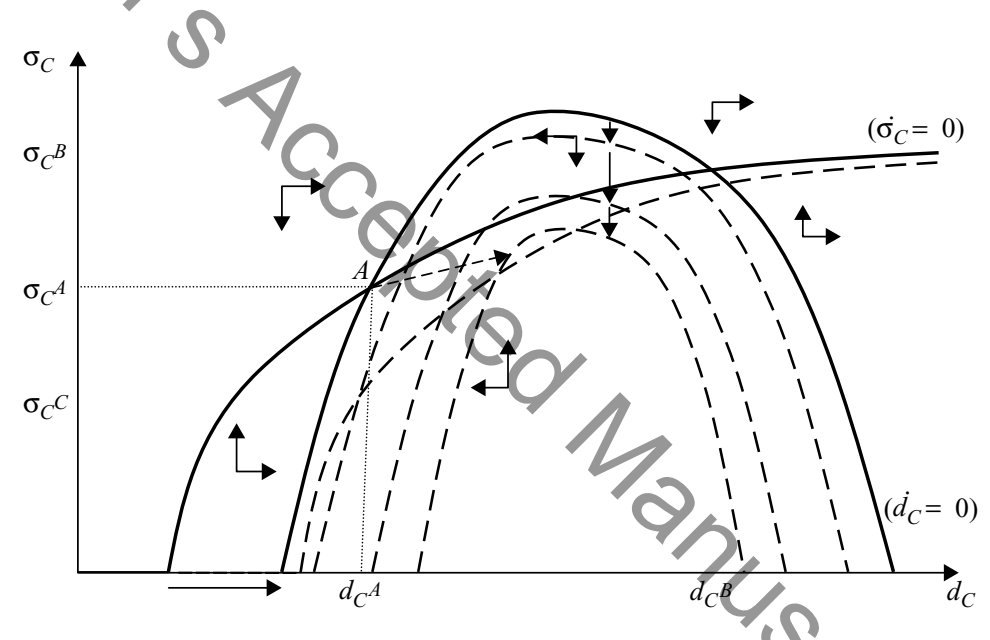

Figure $3 b$ The center's financial instability in the center-big periphery case

a perverse cycle took place, the center-periphery diverging trends would nolonger exist. This scenario seems to be consistent with the most recent data on the state of the eurozone economy. The remarkable economic slowdown registered in 2012 in the center might perhaps be a result, at least partially, of deep recessions in big peripheral countries.

\section{AUSTERITY'S MYOPIA AND THE NEED FOR A EUROPEAN FEDERAL GOVERNMENT}

Diverging trends among eurozone countries may play a decisive role in defining which kind of reforms European institutions will adopt to solve the crisis. Should the crisis persist only in the periphery, it might be perceived as a periphery-specific issue. Accordingly, fiscal restrictions in the periphery, such as those prescribed by the fiscal compact, may appear as the best solution to the crisis (European Central Bank 2012). By contrast, the 
diffusion of the crisis to the center may favor the adoption of a wider reform agenda. It may pave the way towards the creation of a European federal union, admitting more space for a federal expansionary fiscal policy. Let's evaluate these alternatives.

\subsection{Long-run effects of the fiscal compact}

The fiscal compact dictates that eurozone countries must have a structural balance deficit no higher than 0.5 percent of GDP. This ceiling increases to 1 percent of GDP in the case of countries with a debt lower than 60 percent of GDP. Thus, the fiscal compact does not exclude, a priori, expansionary fiscal stances to be adopted in extraordinary cases. Nevertheless, it reiterates stronger than ever before the balanced budget principle as the general rule that eurozone countries must follow. First, such a rule must be enforced throu'gh member states' laws, preferably in constitutional laws. Second, fiscal deficits must be temporary and short-lived, even in the case of temporary deviations justified by extraordinary circumstances.

In our model, the adoption of the fiscal compact modifies the shape of the two loci for $\left(\dot{\sigma}_{C}=0\right)$ and $\left(\sigma_{P}=0\right)$, which depend on primary structural deficits $\Omega_{C}{ }^{*}$ and $\Omega_{P}{ }^{*}$, and on the way they must react to fulfill the fiscal compact's restrictions. Let's assume the fiscal compact applies in the most severe version (structural deficit-to-GDP ratios no higher than 0.5 percent), ${ }^{9}$ so that:

$$
\begin{gathered}
\Omega_{C}^{*}+\left(i^{*}+\sigma_{C}\right) d_{C} \leq 0,005 \rightarrow \Omega_{C}^{*} \leq 0,005-\left(i^{*}+\sigma_{C}\right) d_{C} \rightarrow d_{C}^{*} \\
=\frac{\Omega_{C}^{*}}{\left(g_{C}^{n}+\pi^{T}-i^{*}-\sigma_{C}\right)} \leq \frac{0,005-\left(i^{*}+\sigma_{C}\right) d_{C}}{\left(g_{C}^{n}+\pi^{T}-i^{*}-\sigma_{C}\right)} \\
\Omega_{P}^{*}+\left(i^{*}+\sigma_{P}\right) d_{P} \leq 0,005 \rightarrow \Omega_{P}^{*} \leq 0,005-\left(i^{*}+\sigma_{P}\right) d_{P} \rightarrow d_{P}^{*}= \\
\frac{\Omega_{P}^{*}}{\left(g_{P}^{n}+\pi^{T}-i^{*}-\sigma_{P}\right)} \leq \frac{0,005-\left(i^{*}+\sigma_{P}\right) d_{P}}{\left(g_{P}^{n}+\pi^{T}-i^{*}-\sigma_{P}\right)} .
\end{gathered}
$$

Replace the above expressions for $d_{C}{ }^{*}$ and $d_{P}{ }^{*}$ in the two loci for $\left(\sigma_{C}=0\right)$ and $\left(\dot{\sigma_{P}}=0\right)$. For the sake of simplicity, assume that the above inequalities hold with strict equality signs. We obtain:

$$
\begin{aligned}
& \left(\dot{\sigma_{P}}=0\right) \text { if } d_{P}=d_{P}^{*}=\frac{0,005-\left(i^{*}+\sigma_{P}\right) d_{P}}{\left(g_{P}^{n}+\pi^{T}-i^{*}-\sigma_{P}\right)}, \\
& \text { hence: } d_{P}=\frac{0,005}{\left(g_{P}^{n}+\pi^{T}\right)} \rightarrow\left\{\begin{array}{l}
\dot{\sigma_{P}}<0 \text { if } d_{P}<\frac{0,005}{\left(g_{P}^{n}+\pi^{T}\right)} \\
\dot{\sigma_{P}}=0 \text { if } d_{P}=\frac{0,005}{\left(g_{P}^{n}+\pi^{T}\right)} \\
\dot{\sigma_{P}}>0 \text { if } d_{P}>\frac{0,005}{\left(g_{P}^{n}+\pi^{T}\right)}
\end{array}\right.
\end{aligned}
$$

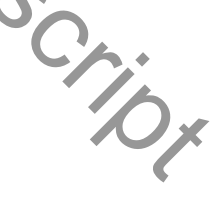

9. By the end of 2012, twelve out of the seventeen eurozone countries have debt stocks higher than 60 percent of GDP. 


$$
\begin{gathered}
\left(\dot{\sigma}_{C}=0\right) \text { if } d_{C}=d_{C}^{*}=\frac{0,005-\left(i^{*}+\sigma_{C}\right) d_{C}}{\left(g_{C}^{n}+\pi^{T}-i^{*}-\sigma_{C}\right)}, \\
\text { hence: } d_{C}=\frac{0,005}{\left(g_{C}^{n}+\pi^{T}\right)} \rightarrow\left\{\begin{array}{l}
\dot{\sigma}_{C}<0 \text { if } d_{C}<\frac{0,005}{\left(g_{C}^{n}+\pi^{T}\right)} \\
\dot{\sigma}_{C}=0 \text { if } d_{C}=\frac{0,005}{\left(g_{C}^{n}+\pi^{T}\right)} \\
\dot{\sigma}_{C}>0 \text { if } d_{C}>\frac{0,005}{\left(g_{C}^{n}+\pi^{T}\right)}
\end{array}\right.
\end{gathered}
$$

In Figures $4 \mathrm{a}$ and $4 \mathrm{~b}$, under the provisions of the fiscal compact, the loci for $\left(\dot{\sigma_{P}}=0\right)$ and $\left(\dot{\sigma}_{C}=0\right)$ now take shape as vertical lines. Furthermore, they lie close to the vertical axis due to the extremely low margins imposed onto structural balance deficits.

In Figure 4a, the periphery's risk factor will decrease for values of the debt-to-GDP ratio that lie on the left side of the locus for $\left(\dot{\sigma}_{P}=0\right)$. Opposite dynamics will emerge should $d_{C}$ be higher than the threshold level $\left(0,005 /\left(g_{P}{ }^{n}+\pi^{T}\right)\right)$. A similar line of reasoning applies to the center (see Figure $4 b$ ).

Once again, in the event of a global recession, the two loci for $\left(\dot{d}_{C}=0\right)$ and $\left(\dot{d}_{P}=0\right)$ will move downwards. In the periphery, huge capital outflows will move the locus for $\left(\dot{\sigma}_{P}=0\right)$ to the left. In the center, the 'flight to quality' will move the locus for $\left(\dot{\sigma}_{C}=0\right)$ to the right. In a center-big periphery scenario, there is still the concrete possibility that overall instability would take place in the eurozone. Graphically, such a scenario corresponds to the case in which the two curves for $\left(\dot{d}_{P}=0\right)$ and $\left(d_{C}=0\right)$ lie on the right of the two loci for $\left(\dot{\sigma_{P}}=0\right)$ and $\left(\dot{\sigma}_{C}=0\right)$, respectively. A sufficient condition for the eurozone's instability to occur reads:

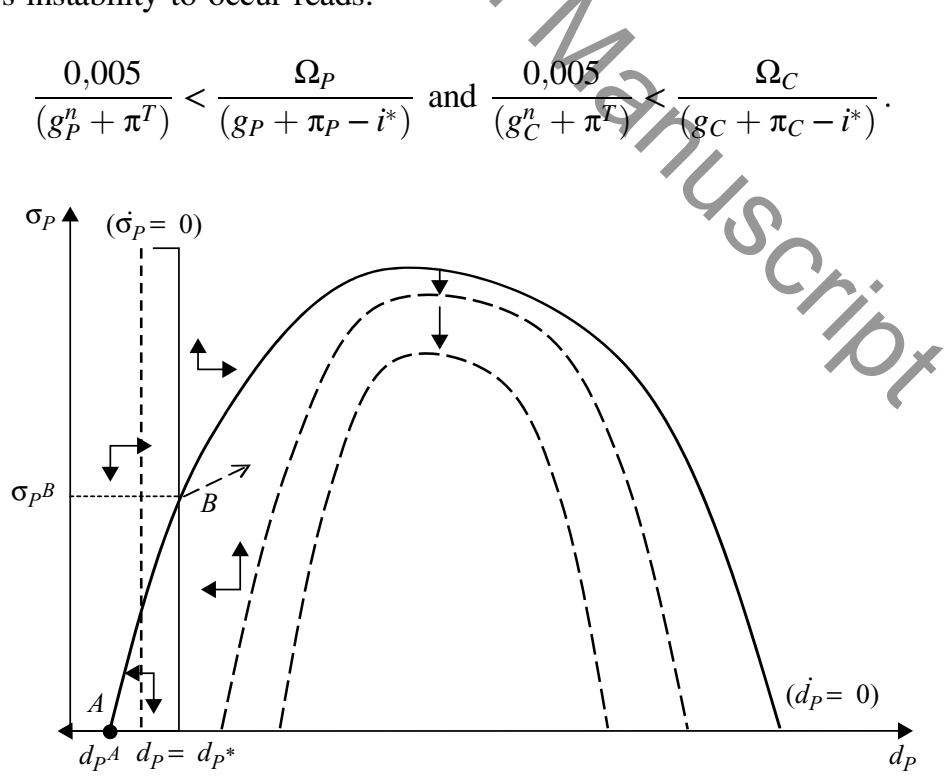

Figure $4 a$ The periphery's financial instability in the presence of the fiscal compact 


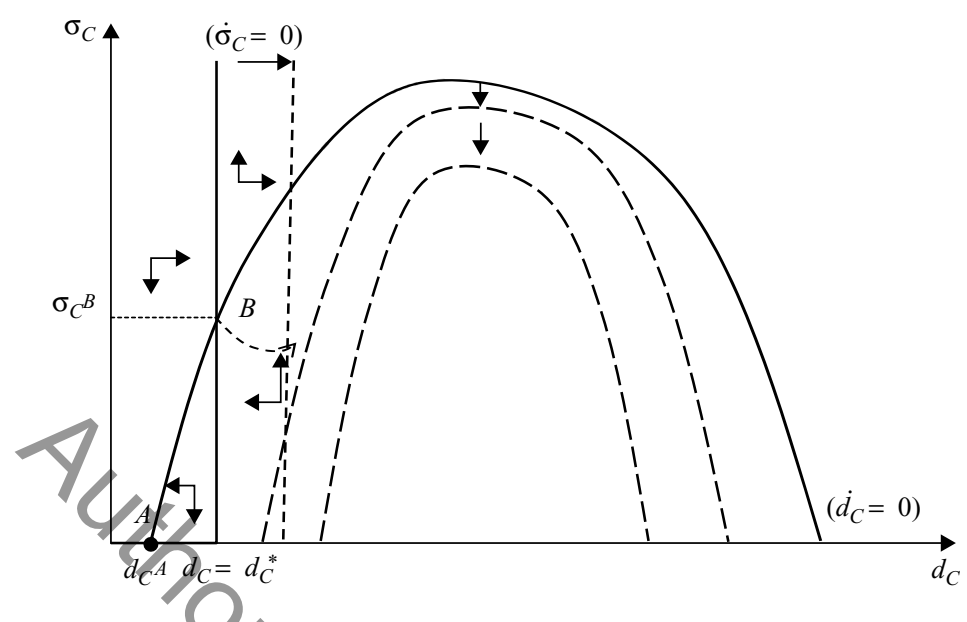

Figure $4 b$ The center's financial instability in the presence of the fiscal compact

According to our analysis, the implementation of the fiscal compact increases overall instability instead of reducing it. First, excessive binding constraints on structural deficits can exacerbate financial markets' reactions in the event of larger-than-expected public balance disarrays. Second, the automatic fiscal correction mechanisms envisaged by the fiscal compact may trigger a peryerse fallacy of composition phenomenon. In the presence of a systemic recession, all eurozone countries will simultaneously implement fiscal corrections. Austerity in the big periphery will jeopardize growth in the center, which, in turn, due to its own stabilization package, will reduce economic activity in the periphery. This event emerges clearly from Equations (11) and (12), in which we show how growth rates in the center and in the periphery react to fiscal restrictions, and are influenced by the economic activity in the partner country ('hat' variables stand for percentage variations):

$$
\begin{gathered}
\widehat{g_{C}}=\epsilon_{g_{C}, G_{C}} \widehat{G_{C}}+\epsilon_{g_{C}, \theta_{C}} \widehat{\theta_{C}}+\epsilon_{g_{C}, g_{P}} \widehat{g_{P}} \\
\widehat{g_{P}}=\epsilon_{g_{P}, G_{P}} \widehat{G_{P}}+\epsilon_{g_{P}, \theta_{P}} \widehat{\theta_{P}}+\epsilon_{g_{P}, g_{C}} \widehat{g_{C}}
\end{gathered}
$$

with $\epsilon_{g_{C}, G_{C}}, \epsilon_{g_{P}, G_{P}}, \epsilon_{g_{C}, g_{P}}, \epsilon_{g_{P}, g_{C}}>0 ; \epsilon_{g_{C}, \theta_{C}}, \epsilon_{g_{P}, \theta_{P}}<0$.

In Equations (11) and (12), $\epsilon$ stands for growth rates' elasticities to fiscal policy variables, and to the partner countries' economic activity. In a center-big periphery scenario, fiscal correction in a single economy (that is, $\widehat{G_{C}}$ and $\widehat{G_{P}}<0 ; \widehat{\theta_{C}}$ and $\widehat{\theta_{P}}>0$ ) will impinge upon economic activity in the partner country via the 'foreign growth' terms $\left(\epsilon_{g_{C}, g_{P}} \widehat{\left.g_{P}\right)}\right.$ and $\left(\epsilon_{g_{P}, g_{C}} \widehat{\left.g_{C}\right)}\right.$. Eventually, the obsession with fiscal austerity will result in a eurozone center-periphery lose-lose game.

\subsection{Stabilization through a European federal fiscal policy}

Consider an alternative reform agenda, whose final goal is the creation of a fully fledged European federal entity. Two aspects are fundamental. First, the creation of 
a European federal government which can dispose of a considerable federal budget and run anti-cyclical fiscal policies that could be financed by issuing European Treasury Bonds. Second, the reformation of the current ECB statute, thus creating a central bank that could operate as a government banker.

In our model, fiscal expansion carried out by a European federal government by means of a federal budget is represented as a (positive) external factor in the macroeconomic picture of central and peripheral economies. This kind of intervention would have three main consequences. First, the costs of anti-cyclical measures and of financial institutions' rescue packages will largely move from national balances to the European federal budget. Accordingly, in the equations for $\left(\dot{d}_{P}=0\right)$ and $\left(\dot{d}_{C}=0\right)$, member states' primary balances $\Omega_{P}$ and $\Omega_{C}$ would be mostly unaffected by the recession. Second, growth could recover more quickly in the center and in the periphery, and it will not be harmed by austerity packages. In the two equations for $\left(\dot{d}_{P}=0\right)$ and $\left(\dot{d}_{C}=0\right), g_{P}$ and $g_{C}$ could be thought to remain broadly unchanged, with positive implications on the solidity of national public balances via the revenue side of public accounts. Ultimately, these facts all work to stabilize the two loci for $\left(\dot{d}_{P}=0\right)$ and $\left(\dot{d}_{C}=0\right)$, which would remain in about the same original position.

A third indirect side-effect of federal fiscal measures is the stabilization of financial markets. Thanks to the intervention of the European federal government, fiscal stimuli to economic activity will not burden national government balances any longer. Consequentially, no fear of national government insolvency will upset financial markets. Speculative forces will not gain strength; liquidity will not dry up in the periphery and move to the center. In our model, the 'shock' $\varepsilon_{P}$ term could be neutralized. The two loci for $\left(\dot{\sigma}_{P}=0\right)$ and $\left(\dot{\sigma}_{C}=0\right)$ would remain stable and not move asymmetrically. The country-risk factors associated with the eurozone countries would not be revised upward.

Expansionary fiscal policies carried out by a European federal government may render single eurozone countries largely immune from the financial consequences of deep recessions. Yet some may argue that considerable Eurobond-financed fiscal deficits may now emerge at the federal level. Could this create a new round of financial turbulences? According to Palley (2011), this event will not occur in the presence of an ECB acting as a government banker. In such an institutional framework, the ECB could act in the same way as the US Federal Reserve and the Bank of England currently do. It could intervene promptly to back Eurobonds' issuances, reduce interest rates and restore financial tranquility in the event of financial distress on the market for Eurobonds. In the presence of such an option, Eurobonds would be hardly subjected to speculative attacks. On the contrary, following De Grauwe(2011), they may appear safe assets in which financial operators may invest money, as long as recession has ended and private assets have returned to the favor of financial operators.

Monetary policies that aim at preventing financial turbulences on a possibly nearto-come Eurobonds market do not correspond to any precise variable in our centerperiphery framework. Yet, from a logical point of view, they might be described as broadly similar to the unlimited bond-buying program the ECB has recently launched, which aims at helping an easier public balance management in member states by reducing debt service costs. In our model, such kinds of intervention obviously affect financial markets' behavior, hence the revision of the country-specific risk factors $\sigma_{P}$ and $\sigma_{C}$. Once again, the ECB's intervention against sovereign debt default will likely induce the 'shock' term $\varepsilon_{P}$ to lose relevance in the equations for $\left(\dot{\sigma}_{P}\right)$ and $\left(\dot{\sigma}_{C}\right)$. Further, the sensitivity parameters $\beta$ and $\delta$ may assume zero-approaching values: financial operators may be induced not to increase $\sigma_{P}$ and $\sigma_{C}$ in response to increasing 
debt-to-GDP ratios in central and peripheral economies. Graphically, the two loci for $\left(\dot{\sigma_{P}}=0\right)$ and $\left(\dot{\sigma_{C}}=0\right)$ would now assume a pretty flat shape, perhaps horizontal lines corresponding to the horizontal axis in the $\left(d_{P}, \sigma_{P}\right)$ and $\left(d_{C}, \sigma_{C}\right)$ space. This type of intervention could strongly improve the financial stability of euro countries. It would give rise to an opposite economic environment with respect to that emerging from the implementation of the fiscal compact. The same is likely to happen in the overall eurozone in the presence of an ECB that will support future Eurobond issuances financing anti-cyclical federal fiscal policies.

\section{CONCLUSIONS}

In the aftermath of the 2007-2008 crisis, the incomplete nature of the euro system - as compared to a fully developed federal union - may have contributed to diverging trends between central and peripheral member states. In turn, such divergences may have prompted the austerity-based reforms adopted so far. Fiscal austerity, however, has obtained disappointing results, and has not interrupted any of the mechanisms behind the eurozone crisis. Here, we formally show that the creation of a European federal government and of a government banker likely represent the decisive steps to solve the current crisis.

The creation of a fully operative monetarily sovereign eurozone federal government is a far-reaching objective. Accordingly, the ECB's unlimited bond-buying program appears to be the most reasonable initiative that policymakers could take to tame the crisis. This monetary measure presents several shortcomings and alone will not be enough to restore growth. Full recovery from the 'Great Recession' will hardly take place without considerable expansionary fiscal stances. Nevertheless, it will be much easier to find room for expansionary stances, both at the national and European level, in the presence of an interventionist monetary policy that fights financial speculation.

\section{REFERENCES}

Bibow, J. (2012), 'The Euro Debt Crisis and Germany's Euro Trilemma, Leyy Economics Institute Working Paper no 721.

Botta, A. (2013), 'Fiscal Policy, Eurobonds and Economic Recovery: Some Heterodox. Policy Recipes against Financial Instability and Sovereign Debt Crisis,' Journal of Post Keynesian Economics, 35 (3), 417-442.

Corsetti, G., A. Meier, and J.M. Gernot (2012), 'What Determines Government Spending Multipliers?', IMF Working Paper no 150.

De Grauwe, P. (2011), 'Managing a Fragile Eurozone,' Cesifo Forum no 2/2011.

European Central Bank (2012), 'A Fiscal Compact for a Stronger Economic and Monetary Union,' ECB Monthly Bulletin, May.

Gandolfo, G. (1996), Economic Dynamics, Berlin: Springer.

Hein, E., A. Truger, and T. van Treeck (2011), 'The European Financial and Economic Crisis: Alternative Solutions from a (Post-)Keynesian Perspective,' IMK Working Paper no 9/2011.

Herndon, T., M. Ash, and R. Pollin (2013), 'Does High Public Debt Consistently Stifle Economic Growth? A Critique of Reinhart and Rogoff,' PERI Working Paper no 322.

IMF (2012), 'World Economic Outlook - Coping with High Debt and Sluggish Growth,' October.

Krugman, P. (2012), End This Depression Now, New York: W.W. Norton Company. 
Lavoie, M. (2006), 'A Post-Keynesian Amendment to the New Consensus on Monetary Policy,' Metroeconomica, 57 (2), 165-192.

León-Ledesma, M.A. and A.P. Thirlwall (2002), 'The Endogeneity of the Natural Rate of Growth,' Cambridge Journal of Economics, 26 (4), 441-459.

Palley, T. (2011), 'Monetary Union Stability: The Need for a Government Banker and the Case for a European Public Finance Authority,' IMK Working Paper no 2/2011.

Papadimitriou, D.B. and L.R. Wray (2012), 'Euroland's Original Sin,' Levy Economics Institute Policy Note no 8/2012.

Perez-Caldentey, E. and M. Vernengo (2012), 'The Euro Imbalances and Financial Deregulation: A Post-Keynesian Interpretation of the European Debt Crisis,' Levy Economics Institute Working Paper no 702.

Reinhart, C.M. and K.S. Rogoff (2010), 'Growth in Time of Debt,' American Economic Review: Papers and Proceedings, 100, 573-578.

Stockhammer, H. (2012), 'Euro-Keynesianism? The Financial Crisis in Europe,' Radical Philosophy, 175, 2-10.

Taylor, L. C.R. Proaño, L. de Carvalho, and N. Barboza (2012), 'Fiscal Deficits, Economic Growth and Government Debt in the USA,' Cambridge Journal of Economics, 36 (1), 189-204.

Waysand, C., K. Ross, and J. de Guzman (2010), 'European Financial Linkages: A New Look at Imbalances,' IMF Working Paper no 10/295.

Wray, L.R. (1998), Understanding Modern Money: The Key to Full Employment and Price Stability, Northampton, MA, USA: Edward Elgar.

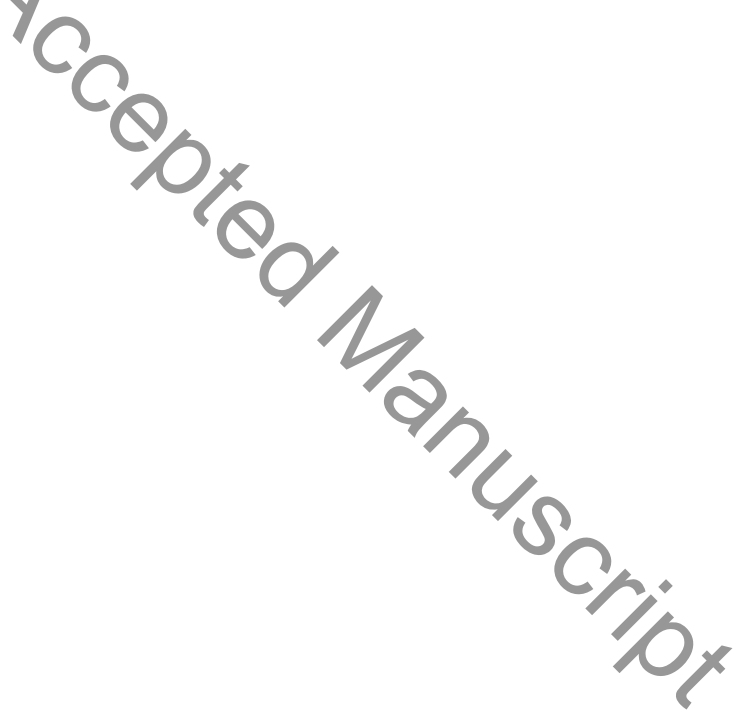


Table A1 Sectoral composition and external balance (percentage of GDP), selected eurozone countries.

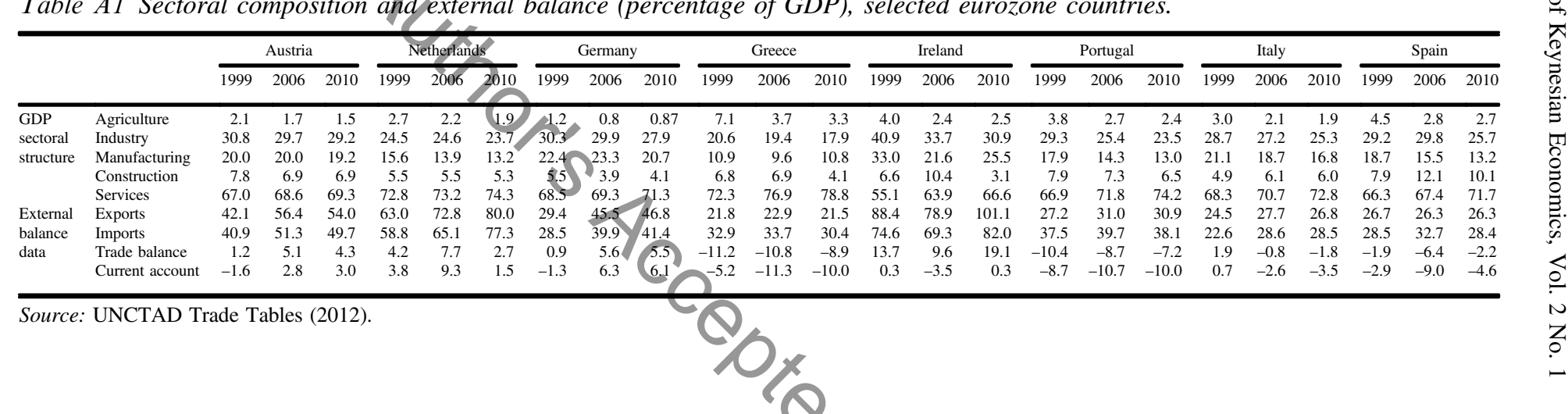

Table A2 Macroeconomic data in selected eurozone countries and other advanced economies (all variables in percentage of GDP)

\begin{tabular}{|c|c|c|c|c|c|c|c|c|c|c|c|c|c|c|c|c|c|c|c|c|c|c|c|c|c|c|c|c|c|c|}
\hline & \multicolumn{3}{|c|}{ Austria } & \multicolumn{3}{|c|}{ Netherlands } & \multicolumn{3}{|c|}{ Germany } & \multicolumn{3}{|c|}{ Greece } & \multicolumn{3}{|c|}{ Ireland } & \multicolumn{3}{|c|}{ Italy } & \multicolumn{3}{|c|}{ Portugal } & \multicolumn{3}{|c|}{ Spain } & \multicolumn{3}{|c|}{ UK } & \multicolumn{3}{|c|}{ US } \\
\hline & $\overline{\Omega+i d}$ & $d$ & $g$ & $\Omega+i d$ & $d$ & $g$ & $\Omega+i d$ & $d$ & $g$ & $\Omega+i d$ & $d$ & $g$ & $\Omega+i d$ & $d$ & $g$ & $\Omega+i d$ & $d$ & $g$ & $\Omega+$ & 2 & $g$ & $\Omega+i d$ & $d$ & $g$ & $\Omega+i d$ & $d$ & $g$ & $\Omega+i d$ & $d$ & $g$ \\
\hline 2007 & -1.0 & 60.2 & 3.7 & 0.1 & 45.3 & 3.9 & 0.2 & 65.2 & 3.4 & -6.7 & 105.4 & 3.0 & 0.1 & 24.8 & 5.2 & -1.5 & 103.1 & 1.7 & -3.2 & 68.3 & 2.4 & 1.9 & 36.3 & 3.5 & -2.8 & 43.7 & 3.6 & -2.7 & 67.2 & 1.9 \\
\hline 2008 & -1.0 & 63.8 & 1.4 & 0.3 & 58.5 & 1.8 & -0.1 & 66.7 & 0.6 & -9.7 & 110.7 & -0.1 & -7.3 & 44.2 & -3.0 & -2.7 & 105.8 & -1.2 & -3.7 & 71.6 & 0.0 & -4.2 & 40.2 & 0.6 & -5.1 & 52.2 & -1.0 & -6.7 & 76.1 & -0.3 \\
\hline 2009 & -4.1 & 69.5 & -3.8 & -5.6 & 60.8 & -3.5 & -3.2 & 74.4 & -5.1 & -15.6 & 127.1 & -3.3 & -14.2 & 65.2 & -7.0 & -5.4 & 116.1 & -5.5 & -10.2 & 83.1 & -2.9 & -11.2 & 53.9 & -3.7 & -10.3 & 68.0 & -4.0 & -13.3 & 89.7 & -3.1 \\
\hline 2010 & -4.5 & 71.8 & 2.3 & -5.1 & 62.9 & 1.6 & -4.3 & 83.2 & 3.6 & -10.6 & 142.8 & -3.5 & -31.3 & 92.5 & -0.4 & -4.5 & 118.7 & 1.8 & -9.8 & 93.4 & $(1.4$ & -9.3 & 61.2 & -0.1 & -9.9 & 75.0 & 1.8 & -11.6 & 98.6 & 2.4 \\
\hline 2011 & -2.6 & 72.2 & 3.1 & -5.0 & 66.2 & 1.3 & -1.0 & 81.5 & 3.1 & -9.2 & 163.3 & -6.9 & -9.9 & 105.0 & 0.5 & -3.9 & 120.1 & 0.3 & -4.0 & 106.8 & -1.5 & -8.5 & 68.5 & 0.5 & -8.6 & 82.0 & 0.8 & -10.1 & 102.9 & 1.8 \\
\hline 2012 & $-2.9 *$ & $74.3 *$ & $0.9^{*}$ & -3.7 & 68.2 & -0.5 & $-0.4^{*}$ & $83 *$ & $1 *$ & $-7.5^{*}$ & $170.7 *$ & $-6.0 *$ & $-8.3 *$ & $118.0^{*}$ & $0.4 *$ & $-2.7 *$ & $126.3^{*}$ & $-2.3 *$ & $-5.0 *$ & $119.0^{*}$ & 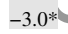 & $-7.0^{*}$ & $9077^{*}$ & $-1.5^{*}$ & $-8.3^{*}$ & $88.7 *$ & $-0.4 *$ & $-8.7^{*}$ & $107.2^{*}$ & 2.8 \\
\hline
\end{tabular}




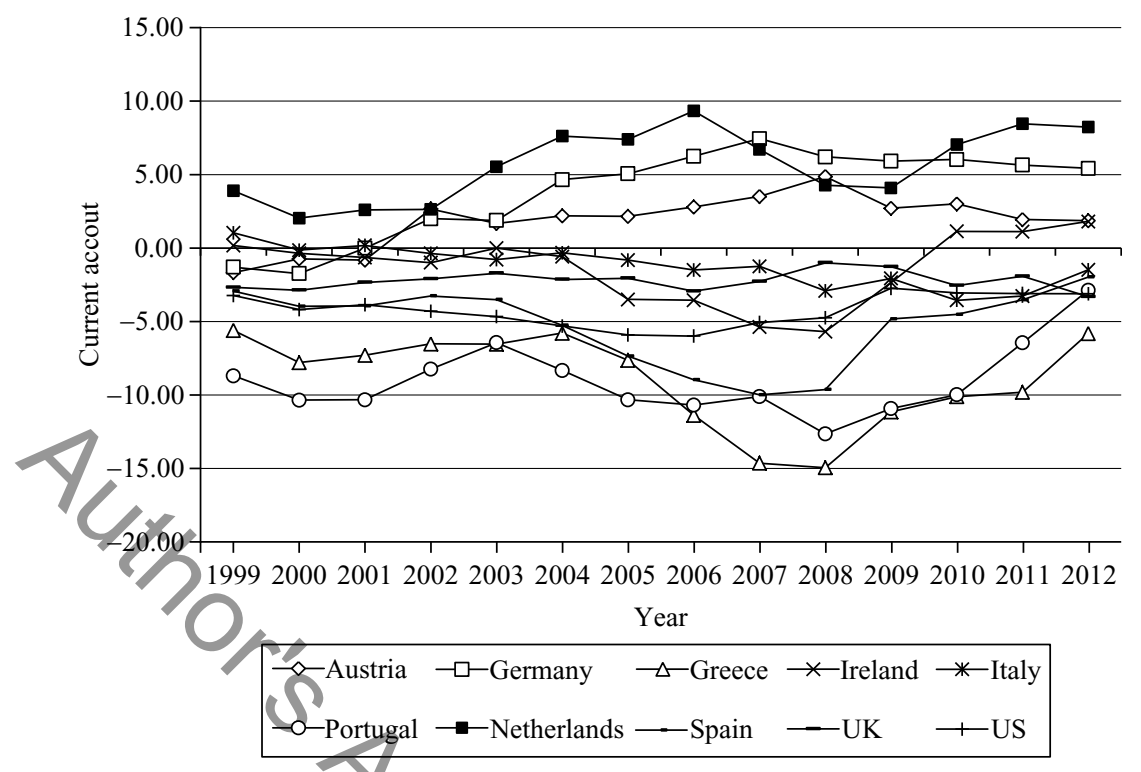

Source: IMF World Economic Outlook (2012).

Figure A1 Current account balance (percentage of GDP), selected euro countries and other advanced economies, 1999-2012

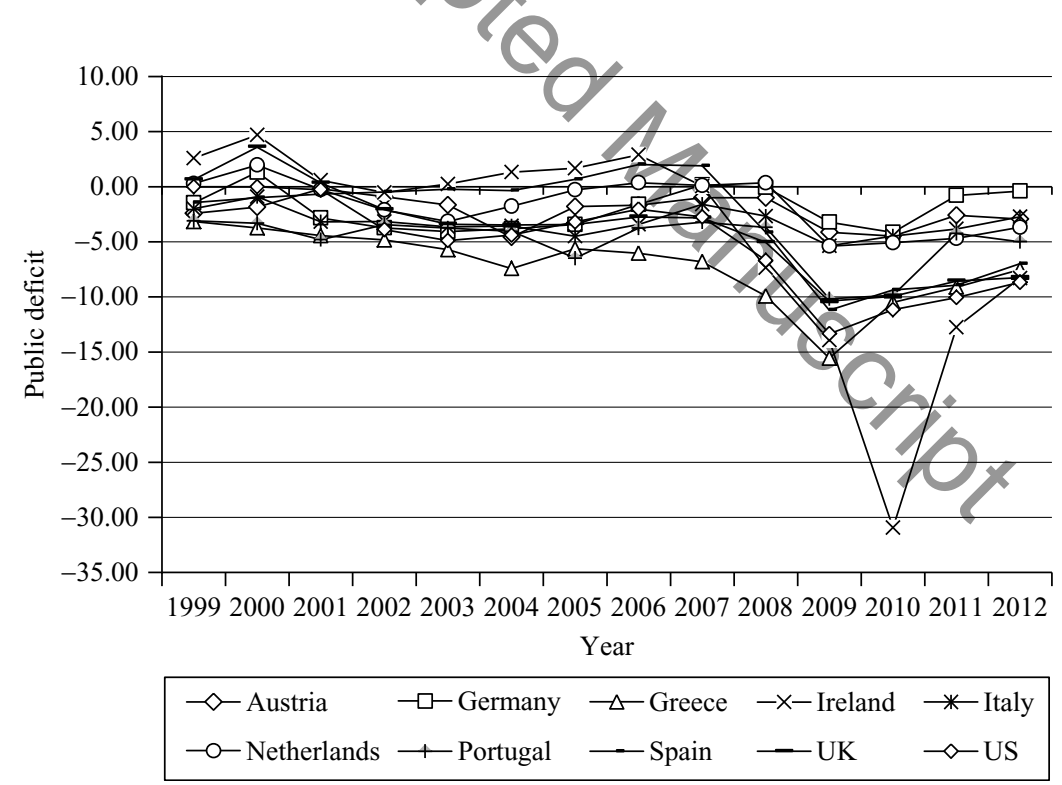

Source: IMF World Economic Outlook (2012).

Figure A2 Public deficit (percentage of GDP), selected euro countries and other advanced economies, 1999-2012 


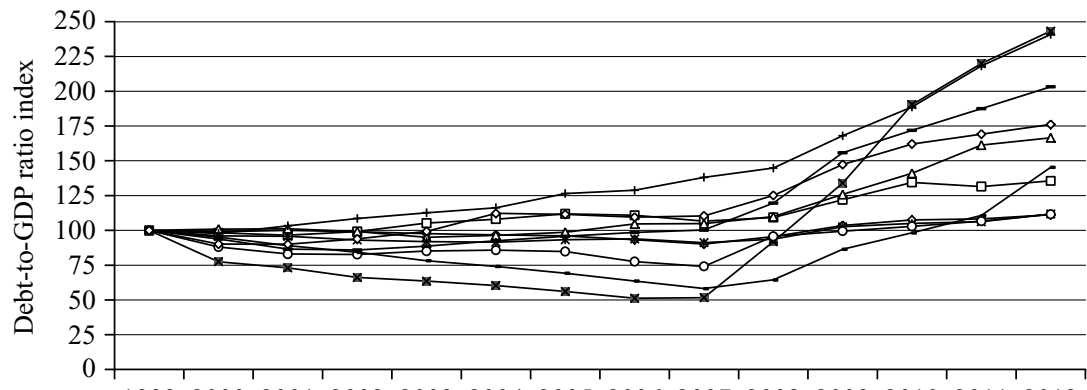
19992000200120022003200420052006200720082009201020112012

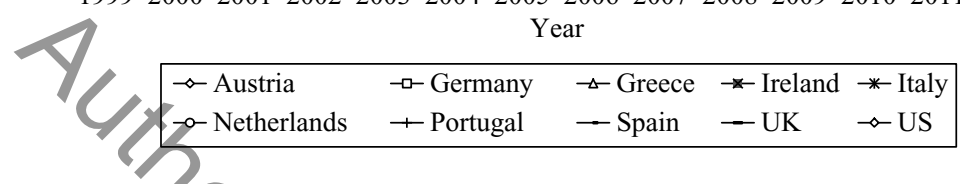

Source: Author's calculations on data from IMF World Economic Outlook (2012).

Figure A3 Debt-to-GDP ratio index, selected euro countries and other advanced economies, 1999-2012 (1999 = base year $)$

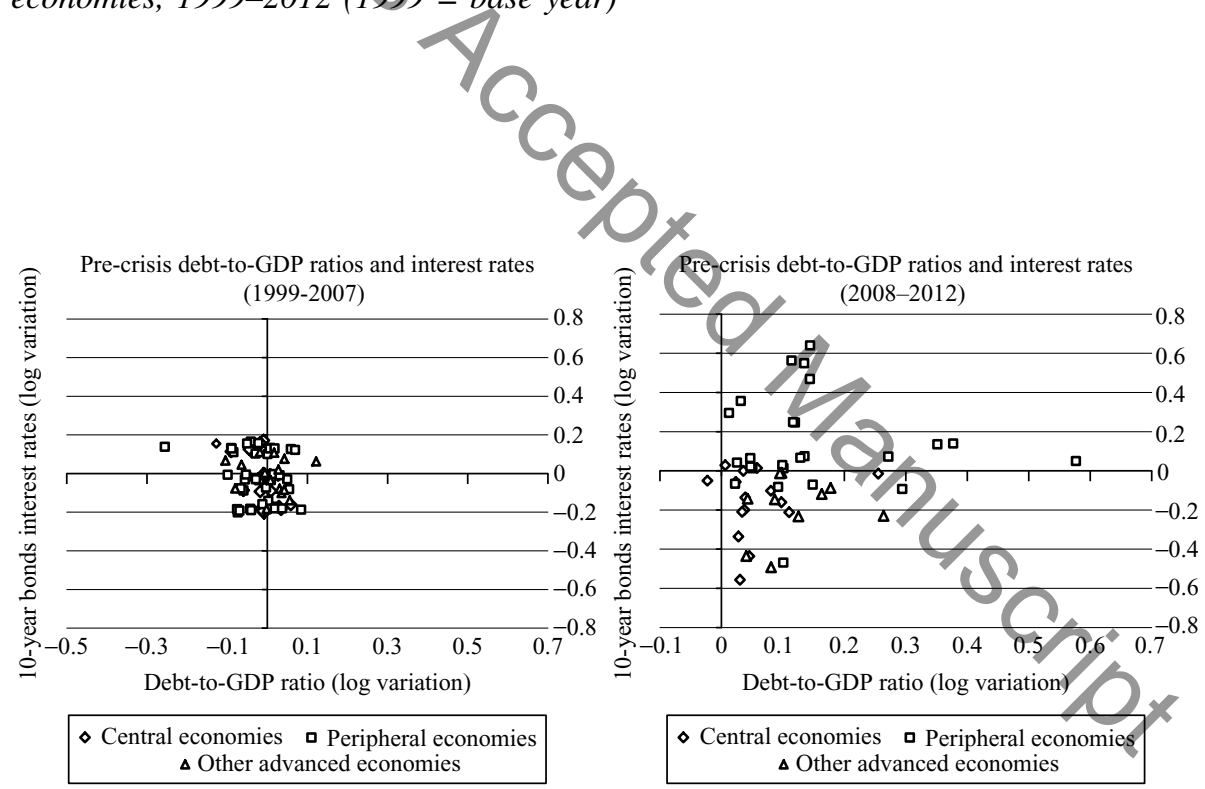

Source: Author's calculations on data from IMF World Economic Outlook (2012).

Figure A4 Asymmetric reaction of financial markets in the aftermath of the 20072008 financial meltdown, peripheral euro countries, central economies, and other advanced economies (UK and US) 


\section{APPENDIX A2}

The Jacobian matrix $J_{C}$ emerging from Equations (7)-(8) reads:

$J_{C}=\left[\begin{array}{ll}\frac{\partial \dot{d}_{C}}{\partial d_{C}} & \frac{\partial \dot{d_{C}}}{\partial \sigma_{C}} \\ \frac{\partial \dot{\sigma_{C}}}{\partial d_{C}} & \frac{\partial \dot{\sigma_{C}}}{\partial \sigma_{C}}\end{array}\right]=$

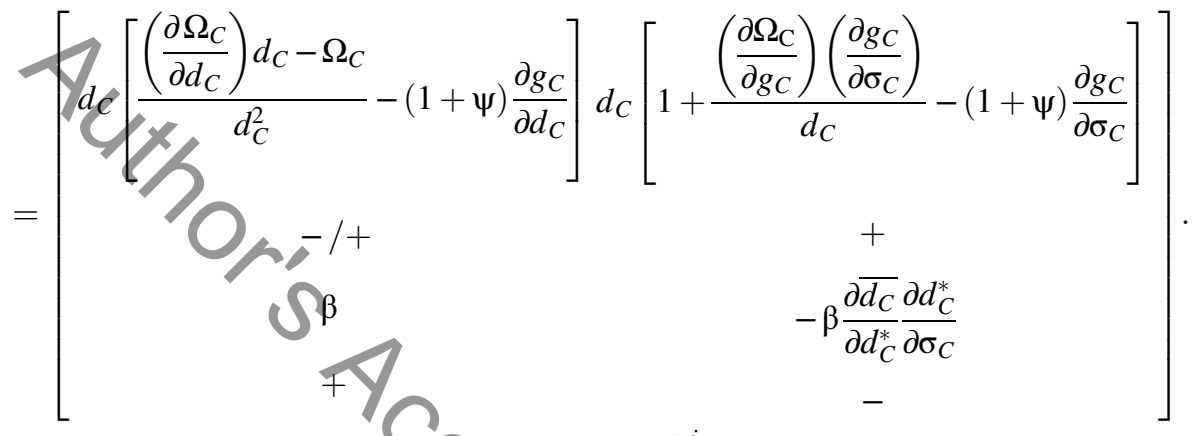

In matrix $J_{C}$, the top-right partial derivative $\left(\frac{\partial \dot{d}_{C}}{\partial \sigma_{C}}\right)$ is positive. First, the higher $\sigma_{C}$ is, the higher the interest rate $i_{C}$, the debt service costs, and the overall public deficit will be. Accordingly, new bonds' issuances, hence $\dot{d}_{C}$, will be larger. Second, note that a higher $\sigma_{C}$ hampers current growth $g_{C}$ through the interest-rate-investment nexus, thus adding further instability to the dynamics of the debt-to-GDP ratio.

According to our formalization of financial markets' behaviors, also $\left(\frac{\partial \dot{\sigma}_{C}}{\partial d_{C}}\right)$ is positive. Ceteris paribus, a higher debt-to-GDP ratio $d c$ will induce financial operators to revise the country-risk factor $\sigma_{C}$ upward.

The partial derivative $\left(\frac{\partial \sigma_{C}}{\partial \sigma_{C}}\right)$ is negative. Ceteris paribus, the higher the country-risk factor $\sigma_{C}$ is, the higher the long-run debt-to-GDP ratio ${ }_{C}^{*}$ will be. In times of financial tranquility, with $\varepsilon_{P}=0$, this will tame financial operators pressures to further revise $\sigma_{C}$ upward. Eventually, self-stabilizing dynamics characterize the evolution of the country-risk factor. The higher $\sigma_{C}$, the more difficult it is that it will newly increase next time.

The partial derivative $\left(\partial \dot{d}_{C} / \partial d_{C}\right)$ deserves a more detailed analysis, since its sign is uncertain. More formally, we have:

$$
\begin{gathered}
\frac{\partial \dot{d}_{C}}{\partial d_{C}}=\frac{d_{C}\left[\frac{\partial \Omega_{C}}{\partial G_{C}} \frac{\partial G_{C}}{\partial d_{C}}+\frac{\partial \Omega_{C}}{\partial \theta_{C}} \frac{\partial \theta_{C}}{\partial d_{C}}+\frac{\partial \Omega_{C}}{\partial g_{C}}\left(\frac{\partial g_{C}}{\partial d_{C}}\right)\right]-\Omega_{C}}{d_{C}^{2}}-(1+\psi)\left(\frac{\partial g_{C}}{\partial d_{C}}\right) \\
\text { with }\left(\frac{\partial \mathrm{G}_{C}}{\partial d_{C}}\right) \leq 0 ;\left(\frac{\partial \theta_{C}}{\partial d_{C}}\right) \geq 0 ;\left(\frac{\partial g_{C}}{\partial d_{C}}\right)=\left[\left(\frac{\partial g_{C}}{\partial G_{C}}\right)\left(\frac{\partial \mathrm{G}_{C}}{\partial d_{C}}\right)+\left(\frac{\partial g_{C}}{\partial \theta_{C}}\right)\left(\frac{\partial \theta_{C}}{\partial d_{C}}\right)\right] \leq 0 .
\end{gathered}
$$

Assume, reasonably, that there is no need for fiscal restrictions when the debt-toGDP ratio is close to zero, so that $\left(\frac{\partial \mathrm{G}_{C}}{\partial d_{C}}\right)=\left(\frac{\partial \theta_{C}}{\partial d_{C}}\right)=0$. Consider also that, consistent with the European rules on fiscal management, in such a safe scenario there is room to run primary fiscal deficits (a positive value of $\Omega_{C}$ ), and that the debt-to-GDP ratio 
doesn't bear any effect on the growth rate $g_{C}$. Assume, finally, that opposite instances would prevail in the case of a much higher debt-to-GDP ratio. In light of these facts, the computation of the limits of $\left(\frac{\partial \dot{d}_{C}}{\partial d_{C}}\right)$ for $d_{C} \rightarrow 0$ and $d_{C} \rightarrow \propto$ demonstrates that:

$$
\begin{gathered}
\lim _{d_{C} \rightarrow 0}\left(\frac{\partial \dot{d}_{C}}{\partial d_{C}}\right)=\frac{-\Omega_{C}}{d_{C}^{2}}=-\infty \\
\lim _{d_{C} \rightarrow \infty}\left(\frac{\partial \dot{d}_{C}}{\partial d_{C}}\right)=\lim _{d_{C} \rightarrow \infty}\left\{\frac{\left[\frac{\partial \Omega_{C}}{\partial d_{C}}\right]}{d_{C}}-\frac{\Omega_{C}}{d_{C}^{2}}\right\}-\lim _{d_{C} \rightarrow \infty}\left[(1+\psi)\left(\frac{\partial g_{C}}{\partial d_{C}}\right)\right]>0 .
\end{gathered}
$$

From an economic point of view, what emerges is that the management of public indebtedness is likely to be easy as long as the debt-to-GDP ratio is low. In such a context, even in the presence of primary fiscal deficits, economic growth may keep the debt-to-GDP ratio stable and under control. By contrast, debt management gets increasingly complex in the case of a high debt-to-GDP ratio $d_{C}$. Actually, tough fiscal policies which produce large primary surpluses may prove to be useless in stabilizing $d_{C}$, due to the recessive effects they produce of economic activity. Eventually, the dynamics of the debt-to-GDP ratio could likely turn out to be unstable.

\section{APPENDIX A3}

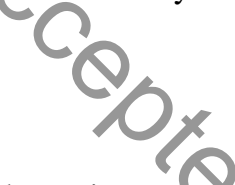

Let us take into consideration the dynamic system composed by Equations (7)-(10) in order to analyse center-periphery dynamics in the case of big economies. The corresponding four-by-four Jacobian matrix $J_{C / B P}$ is:

$$
J_{C / B P}=\left[\begin{array}{ll}
\frac{\partial \dot{d}_{C}}{\partial d_{C}} \frac{\partial \dot{d}_{C}}{\partial \sigma_{C}} & \frac{\partial \dot{d}_{C}}{\partial d_{P}} \frac{\partial \dot{d_{C}}}{\partial \sigma_{P}} \\
\frac{\partial \dot{\sigma}_{C}}{\partial d_{C}} \frac{\partial \dot{\sigma}_{C}}{\partial \sigma_{C}} & \frac{\partial \dot{\sigma}_{C}}{\partial d_{P}} \frac{\partial \dot{\sigma}_{C}}{\partial \sigma_{P}} \\
\frac{\partial \dot{d}_{P}}{\partial d_{C}} \frac{\partial \dot{d}_{P}}{\partial \sigma_{C}} & \frac{\partial \dot{d}_{P}}{\partial d_{P}} \frac{\partial \dot{d}_{P}}{\partial \sigma_{P}} \\
\frac{\partial \dot{\sigma}_{P}}{\partial d_{C}} \frac{\partial \dot{\sigma}_{P}}{\partial \sigma_{C}} & \frac{\partial \dot{\sigma}_{P}}{\partial d_{P}} \frac{\partial \dot{\sigma_{P}}}{\partial \sigma_{P}}
\end{array}\right]
$$

The list of equations below states the partial derivatives (evaluated at the steady state) contained in matrix $J_{C / B P}$. We get:

$$
\begin{aligned}
& \quad \frac{\partial \dot{d}_{C}}{\partial d_{C}}=d_{C}\left[\frac{\left(\frac{\partial \Omega_{C}}{\partial d_{C}}\right) d_{C}-\Omega_{C}}{d_{C}^{2}}-(1+\psi) \frac{\partial g_{C}}{\partial d_{C}}\right] \text { with } \frac{\partial \dot{d}_{C}}{\partial d_{C}}<0 \text { when } d_{C} \rightarrow 0 \text { and } \frac{\partial \dot{d}_{C}}{\partial d_{C}}>0 \text { when } \\
& d_{C} \rightarrow \propto \text {. }
\end{aligned}
$$




$$
\begin{aligned}
& \frac{\partial \dot{d}_{C}}{\partial \sigma_{C}}=d_{C}\left[1+\frac{\left(\frac{\partial \Omega_{C}}{\partial g_{C}}\right)\left(\frac{\partial g_{C}}{\partial \sigma_{C}}\right)}{d_{C}}-(1+\psi) \frac{\partial g_{C}}{\partial \sigma_{C}}\right]>0 \\
& \frac{\partial \dot{d}_{C}}{\partial d_{P}}=d_{C}\left[\frac{\left(\frac{\partial \Omega_{C}}{\partial g_{C}}\right)\left(\frac{\partial g_{C}}{\partial g_{P}}\right)\left(\frac{\partial g P}{\partial d_{P}}\right)}{d_{C}}\right. \\
& \left.-(1+\psi) \frac{\partial g_{C}}{\partial E X_{C}} \frac{\partial E X_{C}}{\partial E X_{C \rightarrow B P}} \frac{\partial E X_{C \rightarrow B P}}{\partial g_{P}} \frac{\partial g_{P}}{\partial d_{P}}\right] \geq 0 \\
& \frac{\partial d_{C}}{\partial \sigma_{P}}=d_{C}\left[\frac{\left(\frac{\partial \Omega_{C}}{\partial g_{C}}\right)\left(\frac{\partial g_{C}}{\partial \sigma_{P}}\right)}{d_{C}}-(1+\psi) \frac{\partial g_{C}}{\partial P_{P}^{T}} \frac{\partial P_{P}^{T}}{\partial i_{P}} \frac{\partial i_{P}}{\partial \sigma_{P}}\right]>0 \\
& \begin{array}{l}
\frac{\partial \dot{\sigma}_{C}}{\partial d_{C}}=\beta>0 \\
\frac{\partial \dot{\sigma}_{C}}{\partial \sigma_{C}}=-\beta \frac{\partial \frac{\partial d_{C}}{\partial d_{C}^{*}} \frac{\partial d_{C}^{*}}{\partial \sigma_{C}}<0}{\partial \sigma_{C}}
\end{array} \\
& \frac{\partial \dot{\sigma}_{C}}{\partial d_{P}}=0 \\
& \frac{\partial \dot{\sigma}_{C}}{\partial \sigma_{P}}=0 \\
& \frac{\partial \dot{d}_{P}}{\partial d_{C}}=d_{P}\left[\frac{\left(\frac{\partial \Omega_{P}}{\partial g_{P}}\right)\left(\frac{\partial g_{P}}{\partial \partial_{C}}\right)\left(\frac{\partial g_{C}}{\partial d_{C}}\right)}{d_{P}}-(1+\chi) \frac{\partial g_{P}}{\partial E X_{P}} \frac{\partial E X_{P}}{\partial E X_{B P} \rightarrow C} \frac{\partial E X_{B P} \rightarrow C}{\partial g_{C}} \frac{\partial g_{C}}{\partial d_{C}}\right] \geq 0 \\
& \frac{\partial \dot{d}_{P}}{\partial \sigma_{C}}=d_{P}\left[\frac{\left(\frac{\partial \Omega_{P}}{\partial g P}\right)\left(\frac{\partial g P}{\partial \sigma_{C}}\right)}{d_{P}}-(1+\chi) \frac{\partial g_{P}}{\partial P_{C}^{T}} \frac{\partial P_{C}^{T}}{\partial i_{C}} \frac{\partial i_{C}}{\partial \sigma_{C}}\right] \geq 0 \\
& \frac{\partial \dot{d}_{P}}{\partial d_{P}}=d_{P}\left[\frac{\left(\frac{\partial \Omega_{P}}{\partial d_{P}}\right) d_{P}-\Omega_{P}}{d_{P}^{2}}-(1+\chi) \frac{\partial g_{P}}{\partial d_{P}}\right] \text { with } \frac{\partial \dot{d}_{P}}{\partial d_{P}}<0 \text { when } d_{P}(\theta) \text { and } \frac{\partial \dot{d}_{P}}{\partial d_{P}}>0 \text { when } \\
& d_{P} \rightarrow \propto . \\
& \frac{\partial \dot{d}_{P}}{\partial \sigma_{P}}=d_{P}\left[1+\frac{\left(\frac{\partial \Omega_{P}}{\partial g_{P}}\right)\left(\frac{\partial g P}{\partial \sigma_{P}}\right)}{d_{P}}-(1+\chi) \frac{\partial g_{P}}{\partial \sigma_{P}}\right]>0 \\
& \frac{\partial \dot{\sigma_{P}}}{\partial d_{C}}=0 \\
& \frac{\partial \dot{\sigma}_{P}}{\partial \sigma_{C}}=0 \\
& \frac{\partial \dot{\sigma}_{P}}{\partial d_{P}}=\delta>0 \\
& \frac{\partial \dot{\sigma_{P}}}{\partial \sigma_{P}}=-\delta \frac{\partial \overline{d_{P}}}{\partial d_{P}^{*}} \frac{\partial d_{P}^{*}}{\partial \sigma_{P}}<0 .
\end{aligned}
$$


According to the derivatives' signs, we're dealing with a Metzlerian matrix. Following Gandolfo (1996), a necessary and sufficient condition for stability requires upper-left minor principals of matrix $J_{C / B P}$ to alternate in sign, starting with a minus sign associated with $\left(\partial \dot{d}_{C} / \partial d_{C}\right)$. Depending on the various signs that some of the above derivatives can assume, several scenarios exist. The above stability condition will be immediately violated in the case of a high debt-to-GDP ratio in the center, such that $\left(\partial \dot{d}_{C} / \partial d_{C}\right)>0$. Let's thus consider the simplest and, say, safest scenario possible in which both the center and the periphery present low values of their own debtto-GDP ratios, so that: $\left(\partial \dot{d}_{C} / \partial d_{C}\right)<0$ and $\left(\partial \dot{d}_{P} / \partial d_{P}\right)<0 ;\left(\partial \dot{d}_{C} / \partial d_{P}\right)=0$ and $\left(\partial \dot{d}_{P} / \partial d_{C}\right)=0$. In this context, we get:

$$
\begin{aligned}
& \begin{array}{c}
\left|J_{C / B P}^{1}\right|=\left|\partial \dot{d}_{C} / \partial d_{C}\right|<0 \\
\left|J_{C / B P}^{2}\right|=\left|J_{C}\right|>0 \\
\int J_{C / B P}^{3}\left|=\left(\partial \dot{d}_{P} / \partial d_{P}\right)\right| J_{C} \mid<0
\end{array}
\end{aligned}
$$

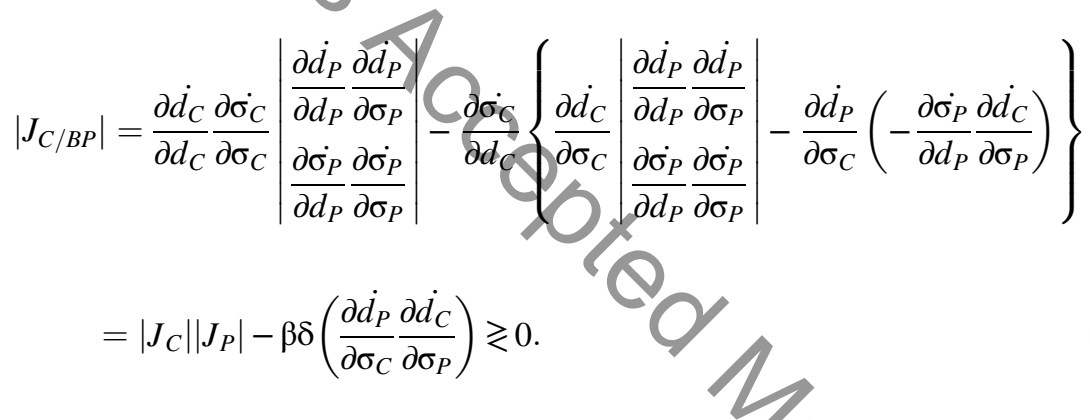

From Equation (13), the sign of $\left|J_{C / B P}\right|$ can be either positive or negative. In the first case, the dynamic system is locally stable. Otherwise, instability arises. Accordingly, in a center-big periphery scenario, stability is not guaranteed even in the safest scenario possible featuring low debt-to-GDP ratios in both the economies. 